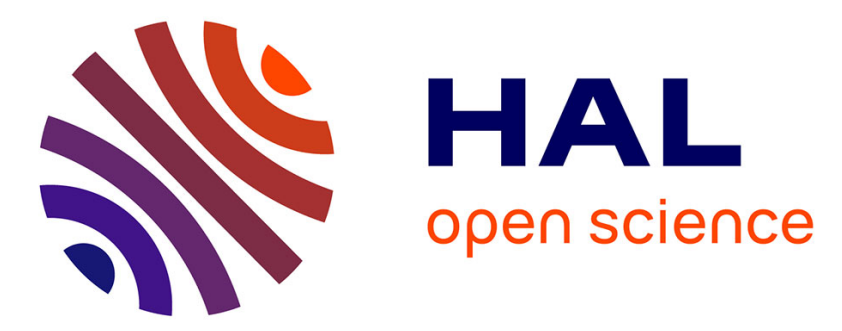

\title{
Heterogeneous impacts of neighbouring farm size on the decision to exit: evidence from Brittany
}

Legrand Dunold Fils Saint-Cyr, Hugo Storm, Thomas Heckelei, Laurent Piet

\section{To cite this version:}

Legrand Dunold Fils Saint-Cyr, Hugo Storm, Thomas Heckelei, Laurent Piet. Heterogeneous impacts of neighbouring farm size on the decision to exit: evidence from Brittany. European Review of Agricultural Economics, 2019, 46 (2), pp.237-266. 10.1093/erae/jby029 . hal-01880459

\section{HAL Id: hal-01880459 \\ https://hal.science/hal-01880459}

Submitted on 25 May 2020

HAL is a multi-disciplinary open access archive for the deposit and dissemination of scientific research documents, whether they are published or not. The documents may come from teaching and research institutions in France or abroad, or from public or private research centers.
L'archive ouverte pluridisciplinaire HAL, est destinée au dépôt et à la diffusion de documents scientifiques de niveau recherche, publiés ou non, émanant des établissements d'enseignement et de recherche français ou étrangers, des laboratoires publics ou privés. 


\title{
Heterogeneous impacts of neighbouring farm size on the deci- sion to exit: evidence from Brittany
}

\author{
Legrand D. F. Saint-Cyr ${ }^{\dagger, *}$, Hugo Storm ${ }^{\ddagger},+$, Thomas Heckelei ${ }^{\ddagger}$ and Laurent Piet $^{\dagger}$ \\ † SMART-LERECO, AGROCAMPUS OUEST, INRA, 35000, Rennes, France \\ $¥$ University of Bonn
}

\begin{abstract}
Accounting for spatial interactions between farms is highly relevant for the analysis of agricultural policy impacts. Existing studies, however, only account for homogeneous (average) spatial interactions. We develop a mixture modelling framework to account for unobserved heterogeneity, allowing spatial interaction to vary across endogenously-defined farm types. We apply this approach to study farmer decisions to exit the farming business using a large panel dataset covering all registered farms in Brittany, France, for the period 2004-2014. While exiting is on average positively correlated with neighbouring farm size, we find substantial variation between farm types, and a negative correlation for a significant proportion of farms. The approach we develop not only enables us to identify different correlations between neighbouring farm size and exits from farming, but it also yields different results than pooled estimations.
\end{abstract}

Keywords: Farm exits, Spatial interactions, Unobserved heterogeneity, Mixture models, EM algorithm

JEL classification: C23, D22, Q12

\section{Introduction}

The farming sector has undergone considerable structural change over the past decades. In most developed countries, the total number of farms has decreased significantly and their average size has increased, implying changes in the distribution of farm sizes (Bollman et al., 1995; Eastwood

${ }^{*}$ Corresponging author Legrand D. F. Saint-Cyr, UMR SMART, AGROCAMPUS OUEST, INRA, 35000, Rennes, France; email:legrand.saintcyr@agrocampus-ouest.fr. Legrand D. F. Saint-Cyr benefitted from a research grant from the Crdit Agricole en Bretagne in the framework of the project 'Enterprises and Agricultural Economics' created in partnership with Agrocampus-Ouest.

${ }^{+}$The work conducted by Hugo Storm is funded by the German Research Foundation (DFG) under grant no. STO 1087/1-1. 
et al., 2010). Understanding the factors that affect farmers' decisions to enter or exit farming, as well as the factors that determine farm growth, has been a concern of agricultural economists and policy makers for quite some time. Weiss (1999), for example, analyses farm survival and growth in Upper Austria, Breustedt and Glauben (2007) examine the exit process for Western European farmers, Dong et al. (2010) study the exit decisions of finisher hog producers in North America, and Aubert and Perrier-Cornet (2009) investigate the factors that influence the survival and growth of small farms in France. Among others, these studies have identified important aspects of structural change in farming and demonstrate that studying farmers exit decisions can help in better understanding farm dynamics in different farming contexts. More recently, Storm et al. (2015) empirically investigate the effects of direct payments on the exit rates of Norwegian farms and show that the spatial interdependence between farms is an important factor in shaping farmer decisions to maintain their production activities. The authors show that accounting for spatial interdependence between farms maybe highly relevant for an aggregate assessment of policy changes in agriculture.

Insofar as most studies addressing neighbour effects estimate the mean effect of neighbouring farm characteristics on farmer decisions (see for example Case (1992); Holloway et al. (2002); Läpple et al. (2017)), they implicitly assume that farmer behaviours are homogeneous in this regard. Storm et al. (2015) also estimate the mean effect of neighbouring farm characteristics on farmer decisions to exit the profession. Results from studies that use this type of estimation approach therefore assume that all farms will behave alike with respect to the investigated characteristics. However, some farms may be more or less sensitive to the characteristics of neighbouring farms (e.g., regarding direct payment received, farm size, etc.), and these differences could arise due to specific individual characteristics. If all of these characteristics were observed, controlling for them would lead to a more efficient estimation of the impacts associated with neighbouring farms. When this is not the case, the resulting parameters may be biased and inconsistent due to unobserved heterogeneity among farms (Kyriazidou, 1997; Pennings and Garcia, 2004). One way to tackle this issue is to use modelling frameworks that are able to control for unobserved heterogeneity among farms.

In this paper, we apply a mixture modelling approach in order to investigate heterogeneity in spatial interactions in the context of farmers' decisions to exit farming. The finite mixture model offers several advantages over other modelling approaches used to control for unobserved heterogeneity, such as fixed and random effects models and random parameter models. In particular, the simplicity and intuitiveness of the finite mixture model makes it relatively straightforward to implement (Greene, 2012; Holloway et al., 2007). Finite mixture models enable observations that are characterised by a similar relationship between dependent and independent variables to be endogenously selected from the data (Holloway et al., 2007). We therefore apply the mix- 
ture modelling approach in order to identify farms that are characterized by similar behaviours regarding the impact of neighbouring producer characteristics.

We develop the mixture modelling approach in order to use it in conjuncture with panel data. Some studies in the literature have already used panel data to study farmer decisions to exit farming (see Landi et al. (2016) for a recent example). However, to the best of our knowledge, we are the first to investigate spatial interactions between farms both using panel data and controlling for unobserved heterogeneity. The fundamental advantage of a panel dataset over a cross-sectional dataset is that the former allows greater flexibility in modelling differences in the behaviour of individuals (Greene, 2012). We therefore expect that using a mixture modelling approach in conjunction with panel data will better describe differences in farmer behaviour through the impacts of neighbouring farm characteristics on farmer decisions to exit farming. However, rather than introducing farm fixed effects, we take advantage of the panel dimension of the data by specifying that the type membership for each farm remains fixed over time. Even though farmer behaviour could conceivably change over time, this is likely to be a long-run rather than a short-run process. We thus implement the mixture model keeping farm type membership constant over time; that is, farmers are not allowed to switch from one endogenous type to another. This approach is consistent with our objective to demonstrate unobserved heterogeneity in farmer behaviour as observed by their repeated responses to specific stimuli such as neighbouring farm characteristics.

This paper is structured as follows. The next section provides theoretical justification for the empirical application of this study. Sections 3 and 4 present the modelling approach and the corresponding estimation procedure, respectively. The data used for our empirical application and explanatory variables for the model specification are presented in Section 5 . Section 6 reports the main results. The last section concludes with some considerations regarding possible improvements of this study for further research.

\section{On heterogeneity in spatial interactions between farms}

The characteristics of neighbouring farms may have important impacts on farm size and/or on a farmer's decision to exit farming. Farmer decisions in this regard can indeed be influenced by their interactions on the real estate market, which is highly localised due to the inherent immobility of the asset in question (Happe et al., 2006). As farms compete for a piece of land, transactions in the real estate market are driven by the differences between farmer willingness to pay (WTP) for land. Focusing on farmer exit decisions, a farm will remain active if its WTP for land is greater than that of its neighbours. This implies that competition in the real estate market depends not only on the characteristics of a given farm, but also on the characteristics of neighbouring farms. Focusing on the specific characteristic of the size of 
neighbouring farms, we extend Storm et al. (2015)'s theoretical framework, providing some additional elements supporting this proposition.

The existing literature distinguishes between two types of effects that neighbouring farms' size can have, both of which originate from technology adoption. On the one hand, neighbours can be viewed as competitors, especially regarding the acquisition of plots (Weiss, 1999). In this case, a farmer whose land is surrounded by larger farms may be forced to shut down his/her operation if these larger farms are quicker to adopt new technologies given that they are likely to have greater access to information and financial resources (Goddard et al., 1993). Neighbours with larger farms therefore have a higher WTP for land, leading neighbouring farm size to have a negative impact on the survival probability of the farm under consideration. On the other hand, neighbours can be considered as a source of motivation and as role models for the adoption of new technologies (Case, 1992; Holloway et al., 2002). In this case, the size of neighbouring farms positively influences the survival of the farm under consideration, because a farmer surrounded by larger farms is more likely to adopt the innovative technologies they use (Harrington and Reinsel, 1995). This could imply an increase in the WTP for land for those neighbouring farms since the adoption of new technology generally means that the farm must acquire enough land in order to optimize its use of the technology.

However, the type of interaction that takes place between neighbours may depend on the farm in question. Indeed, we expect that the effect of neighbouring farms' size will tend to be heterogeneous across the farms we consider, and may depend on the type and characteristics of the farm and farmer considered. One of the most important sources of farm heterogeneity that could notably shape a farmer's behaviour are his/her motivations: neighbouring farms' size is more likely to have an impact (positive or negative) on farmers who are highly motivated by profit maximisation. In the context of free market competition, these business-oriented farms are forced either to innovate or to exit, leaving resources to be acquired by the more innovative competitors in the latter case (Harrington and Reinsel, 1995; Jackson-Smith, 1999). The existence of commercial farms thus depends on their competitiveness, that is, on their capacity to innovate. However, this capacity differs across farms and depends on a variety of factors, such as accessibility to technology and land, managerial capacity, risk perception, attitudes towards risk, etc. (Bowman and Zilberman, 2013; Conradt et al., 2014; Trujillo-Barrera et al., 2016).

However, not all farmers place a high priority on the profit gained through farming activities (Maybery et al., 2005; Howley et al., 2014). Some non-competitive farmers may continue farming due to non-pecuniary motives (Harrington and Reinsel, 1995), perhaps enjoying the farming lifestyle (Hallam, 1991), and may maintain agricultural production at sub-optimal levels (Howley, 2015). This might be the case, for example, among some environmentally-oriented 
farms (Willock et al., 1999) or certain hobby farms (Daniels, 1986; Holloway, 2002). For such farms, new technology is evaluated on criteria other than its financial viability (Mzoughi, 2011). In these cases, the technology is adopted only if it is considered to conform to some predefined criteria that are set by the farmer according to his/her non-pecuniary objectives. Among farmers for whom such motives prevail, one can thus expect a lower (or even no) specific impact of neighbouring farms' size on the probability of remaining in business over time.

Moreover, the motives that shape farmer behaviours (profit maximisation or non-pecuniary motives) are, in fact, unobserved. Indeed, it is difficult to discern what exactly drives the heterogeneity in observed farmer behaviour in the real estate market. Even though farmer motivations may be related to certain farm and/or farmer characteristics, as discussed above, not all of these characteristics are observable. The analysis of farmer exit decisions is therefore a challenging task, one that requires appropriate modelling frameworks that are able to account for unobserved heterogeneity in farmer behaviours.

Based on these considerations, we hypothesise that there are at least two different types of farms that respond to the size of neighbouring farms in different ways: some farms may be more likely to respond negatively to large neighbouring farms' size due to competition for land, which would lead to a positive correlation between farm exit and the neighbouring farm size. Others, in contrast, may be more likely to respond positively in the same situation due to positive spillovers from the adoption of new technologies, which would lead to a negative correlation between farm exit and the size of neighbouring farms. Since both types of response may coexist for each farm, understanding structural change in a specific farming context requires identifying which effect dominates at both the individual and aggregate levels. However, the farm types that may be characterised by different spatial interactions are not observable and must thus be identified endogenously. Given its ability to group observations that are characterised by a similar relationship between dependent and independent variables, the mixture modelling framework mentioned in section 1 above is well-suited to handle this situation. The mixture model applied here is thus able to identify the directions and magnitudes of these different unobserved effect types.

\section{Modelling approach}

To analyse farm survival, we implement a probit model to represent a farmer's decision to exit. The probit model can be understood as a latent utility model in which the latent variable represents the utility that is obtained from staying in or exiting the farming sector. A farmer's utility may be affected by his/her own characteristics as well as by the characteristics of neighbouring farms. The latent variable $y_{i t}^{*}$ underlying the probit model determines the outcome of the farmer's decision to stay in business from one year to the next. Given that we rely on annual 
data regarding farmer decisions, we define:

$$
\begin{array}{ll}
y_{i t}=1 & \text { if } \quad y_{i t}^{*}>0, \quad t=1,2, \cdots, T_{i} \leq T \\
y_{i t}=0 & \text { if } \quad y_{i t}^{*} \leq 0
\end{array}
$$

where $y_{i t}$ is the observed outcome at time $t$ for farm $i$ which takes on the value: $y_{i t}=1$ if the farm remains in farming for two consecutive years, and $y_{i t}=0$ otherwise; $T_{i}$ is the length of time that farm $i$ is observed in the sample.

\subsection{Capturing spatial interactions between farms}

To capture the spatial interactions between farms, we use a spatially-lagged explanatory variable (SLX) specification for the probit model. The latent variable at time $t$ is thus given by:

$$
y_{i t}^{*}=\mathbf{x}_{i t-1} \boldsymbol{\beta}+\mathbf{z}_{i t-1} \boldsymbol{\theta}+\mathbf{q}_{i t-1} \boldsymbol{\gamma}+\epsilon_{i t}, \quad t=1,2, \cdots, T_{i} \leq T
$$

where $\mathbf{x}_{i t-1}$ are own farm characteristics; $\mathbf{z}_{i t-1}$ are neighbouring farms' characteristics; $\mathbf{q}_{i t-1}$ are regional farm characteristics and; $\boldsymbol{\beta}, \boldsymbol{\theta}$ and $\boldsymbol{\gamma}$ are the parameter vectors to be estimated. The disturbances $\epsilon_{i t}$ are T-variate, normally distributed with a $T \times T$ positive definite covariance matrix $\boldsymbol{\Sigma}$.

From a spatial econometric point of view, accounting for neighbouring farms' characteristics through $\mathbf{z}_{i t}$ consists in defining an $n \times n$ dimensional weighting matrix, $\mathbf{W}_{t}$, that indicates which farms are actually neighbouring each other at a specific time $t$, where $n$ is the total number of farms in the sample at time $t$. A value of 1 for $w_{i j t}$ (element of $\mathbf{W}_{t}$ ) indicates that a specific farm $j$ is a neighbour of farm $i$ at a specific time $t$, and 0 otherwise. Because own characteristics are already accounted for in vector $\mathbf{x}_{i t}$, the main diagonal of $\mathbf{W}_{t}$ is by definition set to zero. The $p$ dimensional vector of neighbouring farm characteristics $\left(\mathbf{z}_{i t}\right)$ is then obtained by multiplying the row vector $\mathbf{w}_{i t}$ by the $n \times p$ dimensional matrix of explanatory variables, divided by the row sum of $\mathbf{w}_{i t}$. In doing so, all neighbours are weighted equally (Holloway et al., 2002). For notational simplicity, we omit the weighting matrix $\left(\mathbf{W}_{t}\right)$ in the formulations that follow, using $\mathbf{z}_{i t}$ as the resulting vector of spatially-weighted neighbouring farm characteristics. The SLX model thus makes it possible to identify the impacts of neighbouring farm characteristics on farmer decisions. It also avoids several identification problems that arise in other types of specifications such as the spatial autoregressive model (SAR) (Gibbons and Overman, 2012; Vega and Elhorst, 2015).

Nevertheless, the identification of neighbour effects could still suffer from unobserved and spatially-correlated omitted variables that are correlated to the observed characteristics included in the model (e.g., geographic or historic regional characteristics that could have an impact on farmer exit decisions as well on average farm size in a region). To control for these types of omitted variables we follow Storm and Heckelei (2018) and include average regional farm 
characteristics $\left(\mathbf{q}_{i t}\right)$ as additional explanatory variables. This allows for the effects of farm interactions that take place on a smaller spatial scale to be distinguished from spatial correlations arising from unobserved and spatially-correlated regional characteristics at a larger spatial scale.

All of the explanatory variables in the model are lagged by one year, assuming that farmers make their decisions based on information from previous years. Using lagged explanatory variables also helps to avoid potential endogeneity problems with respect to explanatory variables from the same year, which could arise due to potentially simultaneous and interdependent decision-making processes among neighbouring farms.

\subsection{Accounting for unobserved heterogeneity}

As described in section 2, neighbouring farms' size may influence a farmer's decision in a number ways. To demonstrate the heterogeneity in farmer responses to the characteristics of their neighbouring farms, we apply a mixture modelling approach, which is able to capture unobserved heterogeneity. The mixture modelling approach assumes that the farm population is divided into more than one homogeneous type; each type of farm is characterised by a specific effect of the exogenous variables, including neighbouring farm size, on a farmer's decision. Let $\mathbf{y}=$ $\left(\mathbf{y}_{1}^{T}, \cdots, \mathbf{y}_{n}^{T}\right)$ denote the observed random sample where $\mathbf{y}_{i}$ is the sequence of choices or states of farm $i$ over a certain period of time. Under a mixture approach, the conditional density of $\mathbf{y}_{i}$ is written as (McLachlan and Peel, 2004):

$$
f\left(\mathbf{y}_{i} \mid \Psi\right)=\sum_{g=1}^{G} \pi_{g} f_{g}\left(\mathbf{y}_{i} \mid \mathbf{\Phi}_{g}\right)
$$

where $\boldsymbol{\Psi}=\left(\pi_{1}, \ldots, \pi_{G}, \mathbf{\Phi}_{1}, \ldots, \mathbf{\Phi}_{G}\right)$ are the parameters; $\pi_{g}$ is the probability of belonging to farm of type $g$ with $g=1,2, \cdots, G$, and $f_{g}$ is $g$-type conditional density with parameter $\boldsymbol{\Phi}_{g}$. Since the unobserved types must be exhaustive and mutually exclusive, the $\pi_{g}$ proportions are non-negative and sum to one.

Under this mixture approach, the conditional probability density for the observed data for farm $i$ given the formulation in equation (2) is:

$$
f\left(\mathbf{y}_{i} \mid \mathbf{X}_{i} ; \mathbf{Z}_{i} ; \mathbf{Q}_{i} ; \boldsymbol{\Psi}\right)=\sum_{g=1}^{G} \pi_{g} f_{g}\left(\mathbf{y}_{i} \mid \mathbf{X}_{i} ; \mathbf{Z}_{i} ; \mathbf{Q}_{i} ; \boldsymbol{\Phi}_{g}\right)
$$

where $\boldsymbol{\Phi}_{g}=\left(\boldsymbol{\beta}_{g}, \boldsymbol{\theta}_{g}, \boldsymbol{\gamma}_{g}\right)$ are the parameters to be estimated; and $f_{g}\left(\mathbf{y}_{i} \mid \mathbf{X}_{i} ; \mathbf{Z}_{i} ; \mathbf{Q}_{i} ; \boldsymbol{\Phi}_{g}\right)$ is the respective probability density function specific to farm type $g$. Under the probit formulation in equation (2), the probability density function writes:

$f_{g}\left(\mathbf{y}_{i} \mid \mathbf{X}_{i} ; \mathbf{Z}_{i} ; \mathbf{Q}_{i} ; \boldsymbol{\Phi}_{g}\right)=\prod_{t=1}^{T_{i}}\left[F\left(\mathbf{x}_{i t-1} \boldsymbol{\beta}_{g} ; \mathbf{z}_{i t-1} \boldsymbol{\theta}_{g} ; \mathbf{q}_{i t-1} \boldsymbol{\gamma}_{g}\right)\right]^{y_{i t}}\left[1-F\left(\mathbf{x}_{i t-1} \boldsymbol{\beta}_{g} ; \mathbf{z}_{i t-1} \boldsymbol{\theta}_{g} ; \mathbf{q}_{i t-1} \boldsymbol{\gamma}_{g}\right)\right]^{\left(1-y_{i t}\right)}$ 
where $F\left(\mathbf{x}_{i t-1} \boldsymbol{\beta}_{g} ; \mathbf{z}_{i t-1} \boldsymbol{\theta}_{g} ; \mathbf{q}_{i t-1} \boldsymbol{\gamma}_{g}\right)$ is the cumulative density function of the normal distribution for farm type $g$ and $y_{i t}$ is the observed outcome at time $t$. In the interest of simplicity and saving space, in the following we replace the expression on the right-hand side of equation (5) by $\prod_{t=1}^{T_{i}} f_{g}\left(y_{i t} \mid \mathbf{x}_{i t-1} ; \mathbf{z}_{i t-1} ; \mathbf{q}_{i t-1} ; \boldsymbol{\Phi}_{g}\right)$.

\section{Model estimation}

The mixture model described in the previous section is estimated using the maximum likelihood method via the expectation-maximisation (EM) algorithm. Assuming that observations are independent within farm types given $\mathbf{x}_{i t-1}, \mathbf{z}_{i t-1}$ and $\mathbf{q}_{i t-1}$, the log-likelihood (LL) function for the parameters $\boldsymbol{\Psi}$ of the model, conditional on observing $\mathbf{y}_{i}$, is written as:

$$
L L(\boldsymbol{\Psi})=\sum_{i=1}^{N} \ln \left\{\sum_{g=1}^{G} \pi_{g} \prod_{t=1}^{T_{i}} f_{g}\left(y_{i t} \mid \mathbf{x}_{i t-1} ; \mathbf{z}_{i t-1} ; \mathbf{q}_{i t-1} ; \mathbf{\Phi}_{g}\right)\right\}
$$

where $f_{g}\left(y_{i t} \mid \mathbf{x}_{i t-1} ; \mathbf{z}_{i t-1} ; \mathbf{q}_{i t-1} ; \mathbf{\Phi}_{g}\right)$ is the conditional density function for the probit as given in equation (5). To take into account the panel dimension of the data, the likelihood function is written considering the set of observations for each farm in the sample. The probability of belonging to a specific farm type is thus invariant over time. Indeed, even though farms could switch from one farm type to another, we assume that this is more likely to happen in the long run, based on the discussion in Section 2.

\subsection{Implementing the Expectation-Maximisation (EM) algorithm}

Since farm type is a priori unknown, the EM algorithm is used to estimate the model parameters. The EM algorithm simplifies the complex log-likelihood in equation (6) into a set of easily solvable log-likelihood functions by treating the unobserved farm type as missing information (McLachlan and Krishnan, 2007). Let $v_{i g}$ be a discrete unobserved variable indicating the type of each farm. The random vector $\mathbf{v}_{i}=\left(v_{i 1}, v_{i 2}, \cdots, v_{i G}\right)$ is thus $g$-dimensional with $v_{i g}=1$ if farm $i$ belongs to type $g$, and 0 otherwise. Assuming that $v_{i g}$ is unconditionally multinomially distributed with probability $\pi_{g}$, and conditional on observing $\mathbf{y}_{c}=(\mathbf{y}, \mathbf{v})$, the complete likelihood function writes:

$$
L_{c}(\mathbf{\Psi})=\prod_{i=1}^{N} \prod_{g=1}^{G}\left\{\pi_{g} \prod_{t=1}^{T_{i}} f_{g}\left(y_{i t} \mid \mathbf{x}_{i t-1} ; \mathbf{z}_{i t-1} ; \mathbf{q}_{i t-1} ; \mathbf{\Phi}_{g}\right)\right\}^{v_{i g}}
$$

The complete log-likelihood $\left(L L_{c}\right)$ then writes:

$$
L L_{c}(\boldsymbol{\Psi})=\sum_{i=1}^{N} \sum_{g=1}^{G} v_{i g} \ln \left\{\pi_{g} \prod_{t=1}^{T_{i}} f_{g}\left(y_{i t} \mid \mathbf{x}_{i t-1} ; \mathbf{z}_{i t-1} ; \mathbf{q}_{i t-1} ; \mathbf{\Phi}_{g}\right)\right\}
$$

In this case, $v_{i g}$ is called the 'posterior' probability that farm $i$ belongs to type $g$ given $\mathbf{y}_{i}$, that is $P\left(v_{i g}=1 \mid \mathbf{y}_{i}\right)$, while $\pi_{g}$ is the 'prior' probability of the mixture (McLachlan and Peel, 2004). 
The expression in equation (8) can then be divided into two components:

$$
\begin{aligned}
& L L_{1}=\sum_{i=1}^{N} \sum_{g=1}^{G} v_{i g} \ln \pi_{g} \\
& L L_{2}=\sum_{i=1}^{N} \sum_{g=1}^{G} v_{i g} \sum_{t=1}^{T_{i}} \ln f_{g}\left(\mathbf{x}_{i t-1} ; \mathbf{z}_{i t-1} ; \mathbf{q}_{i t-1} ; \mathbf{\Phi}_{g}\right)
\end{aligned}
$$

Since the farm type is not observed, the posterior probability that farm $i$ belongs to type $g$ (i.e., $v_{i g}$ ) must be estimated from the observations. The EM algorithm therefore consists of the following four steps (Dempster et al., 1977):

(i) Initialisation: Arbitrarily choose initial values $\boldsymbol{\Psi}^{0}=\left(\pi_{1}^{0}, \ldots, \pi_{G}^{0}, \boldsymbol{\Phi}_{1}^{0}, \ldots, \boldsymbol{\Phi}_{G}^{0}\right)$ for the parameters of the model, assuming that the sample consists of $G$ homogeneous farm types.

(ii) Expectation: At iteration $p+1$ of the algorithm, compute the expected probability that farm $i$ belongs to a specific type $g$ while observing $\mathbf{y}_{i}$ and given the parameters $\Psi^{(p)}$. This conditional expectation probability, that is, the 'posterior' probability $v_{i g}^{(p+1)}=v_{i g}\left(\mathbf{y}_{i} ; \Psi^{p}\right)$, can be obtained according to Bayes' law:

$$
v_{i g}^{(p+1)}=\frac{\pi_{g}^{(p)} \prod_{t=1}^{T_{i}} f_{g}\left(y_{i t} \mid \mathbf{x}_{i t-1} ; \mathbf{z}_{i t-1} ; \mathbf{q}_{i t-1} ; \mathbf{\Phi}_{g}^{(p)}\right)}{\sum_{h=1}^{G} \pi_{h}^{(p)} \prod_{t=1}^{T_{i}} f_{h}\left(y_{i t} \mid \mathbf{x}_{i t-1} ; \mathbf{z}_{i t-1} ; \mathbf{q}_{i t-1} ; \mathbf{\Phi}_{h}^{(p)}\right)}
$$

Replacing $v_{i g}$ by its expected value in equation (8) yields to the conditional expectation of the complete data log-likelihood.

(iii) Maximisation: Update $\mathbf{\Psi}^{p}=\left(\pi_{1}^{p}, \ldots, \pi_{G}^{p}, \boldsymbol{\Phi}_{1}^{p}, \ldots, \boldsymbol{\Phi}_{G}^{p}\right)$ by maximising the complete loglikelihood conditional on the observations, given by $L L_{1}+L L_{2}$ in equation (9). The model parameters specific to each farm type are thus updated from $L L_{2}$ as:

$$
\mathbf{\Phi}_{g}^{(p+1)}=\operatorname{argmax}_{\boldsymbol{\Phi}_{g}} \sum_{i=1}^{N} \sum_{g=1}^{G} v_{i g}^{(p+1)} \sum_{t=1}^{T_{i}} \ln f_{g}\left(y_{i t} \mid \mathbf{x}_{i t-1} ; \mathbf{z}_{i t-1} ; \mathbf{q}_{i t-1} ; \boldsymbol{\Phi}_{g}\right)
$$

The maximisation process of equation (11) is straightforward. The parameters of the model $\left(\hat{\mathbf{\Phi}}_{g}^{(p)}\right)$ are updated considering $v_{i g}\left(\mathbf{y}_{i} ; \mathbf{\Psi}^{(p)}\right)$ as weighting factors for each farm $i$. The 'prior' probability of belonging to type $g$ is then updated from $L L_{1}$ as:

$$
\pi_{g}^{(p+1)}=\frac{\sum_{i=1}^{N} v_{i g}^{(p+1)}}{\sum_{i=1}^{N} \sum_{h=1}^{G} v_{i h}^{(p+1)}}, \quad \forall g \in G
$$

(iv) Iteration: Return to expectation step (ii) using $\boldsymbol{\pi}^{(p+1)}$ and $\boldsymbol{\Phi}^{(p+1)}$ and iterate steps (ii) and (iii) until the observed log-likelihood given by equation (6) converges.

At convergence, the resulting parameters $(\hat{\mathbf{\Psi}})$ are considered to be optimal. Due to the potential presence of a high number of local maxima (Hess et al., 2007), the EM algorithm must be run several times with various randomly chosen initial values, and those providing the largest likelihood at convergence are retained as the best ones. 


\subsection{Choosing the optimal number of farm types}

Despite our intuition regarding the relationships between farms as described in Section 2, we have no a priori information about the optimal number of unobserved homogeneous farm types that may exist in a specific farming context. The total number of components for the mixed probit model are thus chosen based on information criteria. The selected criteria are derived from the resulting value of the log-likelihood of the corresponding model $L L_{G}(\mathbf{y} ; \hat{\mathbf{\Psi}})$ for a total of $G$ homogeneous types. The basic principle under these information criteria is parsimony, that is, all other things being equal, the model with fewer parameters is preferred (Andrews and Currim, 2003). The selection criteria can thus be derived from the following formula:

$$
C_{G}=-2\left\{L L_{G}(\mathbf{y} ; \hat{\mathbf{\Psi}})\right\}+\kappa N_{G}
$$

where $L L_{G}(\mathbf{y} ; \hat{\mathbf{\Psi}})$ is the overall population log-likelihood value computed with the resulting estimated parameters for a model specified with $G$ types; $N_{G}$ is the total number of free parameters in the model; and $\kappa$ is a penalty constant.

Depending on the value chosen for $\kappa$, we obtain the well-known Akaike Information Criterion (AIC) if $\kappa=2$, and Bayesian the Information Criterion (BIC) if $\kappa=\ln (N)$ where $N$ is the total number of observations in the sample. However, based on Monte Carlo simulations, it has been shown that the modified AIC (AIC3) with $\kappa=3$ and the consistent AIC (CAIC) with $\kappa=\ln (N)+1$ are preferable to the basic AIC and BIC since they more severely penalise the addition of parameters (Andrews and Currim, 2003). For all of these criteria, smaller values mean more parsimonious models, that is, the lower the information criteria, the more preferable the specification.

\section{Empirical application to farm exits in Brittany}

\subsection{Data used}

For our empirical application, we use data provided by the 'Mutualité Sociale Agricole' (MSA), the French authority for farmer healthcare and social security. The MSA database contains information about individuals who declared that they carry out a non-salaried farming activity in France, and as well as information their farm. Information is collected annually and is available for farmers who were active on January 1st of each year, from 2004 to 2014. The database can be considered almost exhaustive for the French farm population, ${ }^{1}$ so we can assume that a farm: i) begins business if it enters the database after 2004; ii) exits farming if it leaves the database

\footnotetext{
${ }^{1}$ The database is considered as 'almost' exhaustive only because it does not survey the smallest farms as they do not contribute to the MSA, along with corporate farms employing only a salaried workforce.
} 
before 2014; iii) survives if it remains in the MSA database for two consecutive years. ${ }^{2}$

The MSA data required several preparatory treatments before it could be used for analysis. Here we only mention the most significant ones. First, the data had to be consolidated at the farm level because the MSA collects information at the level of the affiliated physical person, i.e., at the level of the farm holder and not the farm itself. This is made possible because each individual person is assigned to the farm number that he/she operates. Second, the utilised agricultural area (UAA) must be aggregated at the farm level with care because it is not simply the sum of the areas reported for each partner of the farm. Indeed, the recorded UAA at the individual partner level is calculated with respect to the proportion of the total capital shares of the farm he/she holds. Thus, whenever one or several partners are not affiliated with the MSA because they are external to the farming sector, shares in the database do not sum to one, and the total UAA must then be computed, taking into account the fact that a part of it accrues to partners who are not observed in the database. Third, in cases where the farm is run by several partners, assumptions must be made for other farm-level variables. This is typically the case for age, farming specialisation and legal status. Concerning age, a choice is made about which partner's age is associated with the farm. Here, we choose the partners' median age as a proxy at the farm level so as not to bias this variables towards either younger or older ages. ${ }^{3}$ The specialisation of the farm is determined from the category of professional risks each partner is registered for. In the database, 16 such risk categories exist, such as 'cereals and industrial crops', 'dairy cattle breeding', 'pig farming', 'wine growing', etc. If the farm includes several production units (e.g., a 'crop' unit plus a 'livestock' unit in dairy farms), each partner may subscribe to only one of the corresponding professional risks depending on the unit he/she specialises in. Therefore, several such risk categories may coexist on the same farm and they must be consolidated so as to avoid a high prevalence of farms being classified as 'mixed farms'. Here, we chose to assign the farm to the risk category that covered at least two-thirds of the partners. Whenever such a majority did not exist, only then did we classify the farm as mixed. In the last step, the MSA risk categories were translated into 13 'types of farming' (farm specialisation) chosen from the nomenclature used by the French agricultural statistics

\footnotetext{
${ }^{2}$ Note that we found 1,109 farms (about 3\% of the sample) that left and then re-entered the database over the studied period. It appears that such cases are likely to correspond to farms whose contribution to the healthcare and social security fund was temporarily suspended for administrative reasons. Since such cases do not actually correspond to true exits or entries, they were excluded from the sample in order to avoid spurious counting.

${ }^{3}$ While the presence of young partners may ensure the continued farm operation over time, older partners may also contribute their experience and capital, which could contribute managing the farm more efficiently. Based on these considerations, we selected the median age of farm holders as a compromise that may better reflect the balance between younger and older partners than the average. A sensitivity analysis (not reported but available upon request) shows that the results are robust to replacing the median age with the age of the youngest partner.
} 
office for the agricultural census and related surveys. Finally, while a farm's legal status should be the same for all partners of a farm, it appeared that this was not so in some cases. In these situations, we assigned the most prevalent legal status (i.e., the mode of the observed values) or, when this was not possible due to the presence of several modes, we assigned the status associated with the higher form of incorporation.

In this empirical application, we restricted our investigation to farms located in Brittany (Western France), which is one of the largest agricultural regions in the country. The unbalanced panel consists of a total of 317,242 observations, with an average exit rate of about $3 \%$ per year from 2004 to 2014

\subsection{The dependent variable and farm-level explanatory variables}

To analyse farmer decisions to exit the farming business, the dependent variable takes the value 1 if the farm remains in business, and 0 otherwise. Since we consider all farms, whatever their production specialisation or legal status, a farm is said to survive from one year to the next if it remains present in the database for these two consecutive years.

The MSA database contains only a few variables that can be used to explain farmer decisions to exit from farming. We thus chose to concentrate on the possible impacts of this limited set of available variables (see Table 1). Farm size in terms of total UAA (area), farm agricultural profit per partner (agri_profit), and the median age of farm holders (median_age), among others, are farm characteristics that may play a role in the probability of remaining in or exiting from farming. Both farm size and agricultural profit are expected to positively influence the probability of remaining in farming because such farm characteristics may increase the farm's WTP for land. While the total land in use is a proxy for path dependency, the total agricultural profit divided by the total number of partners on the farms indicates whether or not farming is a profitable activity. Area squared and age squared are used to capture non-linear effects of the farm size and the age of farm holder on the probability of remaining in farming. Indeed, even though smaller farms may face more credit constraints, larger farms may be less resilient to economic shocks. The age of farmers may be positively related to the probability of remaining in farming, since experience and skill may increase over the years; in contrast, older farmers, especially those close to retirement, may be less motivated to either compete for land or to adjust their operating size over time, leading to the opposite effect. Because a farm's WTP for land may decrease at retirement time despite high agricultural profits, we control for this possible impact by using an interaction term between farm agricultural profit and a dummy variable indicating whether the farmer is close to retirement (agr_profit___retirement). According to the MSA, the minimum age for retirement in France is 60 but farmer behaviour may begin to change even earlier. Since some studies have indeed shown that a farmer's succession is prepared between five and 10 years 
in advance (Gaté and Latruffe, 2016), we choose to consider farmers who are 55 and older as falling in the category of close to retirement. ${ }^{4}$

To capture the relevance of land with regard to the probability of remaining in farming, we define three dummy variables: lowlanduse takes the value 1 if the farm specialises in a production system where average farm size is less than 20 hectares, and 0 otherwise; middlelanduse takes the value 1 if the farm specialises in a production system where average farm size is between 20 and 50 hectares, and 0 otherwise and; highlanduse takes the value 1 if the farm specialises in a production system where the average farms size is more than 50 hectares, and 0 otherwise. This classification is based on the distribution of farm sizes within the sample. In Brittany, production systems that use little land on average tend to be specialised in horticulture, market gardening and cereal-fed livestock other than pigs, while farms that use more land on average are dairy farms, pig farms and mixed (crop and/or livestock) farms. Land is important for livestock farms in order to produce their own feed grain, to provide grazing space, and to distribute animal waste. We thus expect a higher probability of exiting from farming for these types of farms than for other farm specialisations. To directly capture the importance of land for these farms to remain in farming, we include an interaction term between the dummy variable for farms that use large amounts of land and farm area (highlanduse_- $\times_{-}$area). Corporate farms are assumed to have a higher probability of surviving because these farms are generally in a better position to compete for land given that they may have lower financial and credit constraints. We thus use a dummy variable, corporate, that takes the value 1 if the farm operates under a corporate legal status, and 0 otherwise. These variables are included in the model specification in order to capture observed heterogeneity among farms.

\subsection{Spatial explanatory variables}

A second limitation of the MSA database is that no information is available regarding the precise geographic location of the farmstead and farm plots. It is therefore impossible to determine the actual distance between farms. The municipality where the farmstead is located constitutes the finest spatial information available in the database. We thus consider the municipality to be the spatial zone within which farms compete for land. All farms whose farmstead are located in the same municipality are considered as neighbours and are used in the computation of spatially-weighted neighbouring farm characteristics as discussed in Section 3.1. Farms in the selected sample are located in 1,252 municipalities out of the 1,270 in Brittany and have an average area of 21 square kilometers, with a standard deviation of $12 \mathrm{~km}^{2}$. The average number

\footnotetext{
${ }^{4} \mathrm{~A}$ sensitivity analysis was performed varying the threshold between 55 and 60 years to account for the potential effect that anticipating retirement could have on farmer decisions, yielding robust results. The results, not reported here, are available upon request.
} 
of farms per municipality in the sample is 64 , with a standard deviation of 38 . Even though farms may compete for land in other neighbouring municipalities, we suppose that average farm characteristics at the municipality level are good proxy for neighbouring farm characteristics, as it has been shown that more than $75 \%$ of land transactions occur among farms located in the same municipalities (Temesgen, 2014; AGRESTE-Bretagne, 2017). We nonetheless conduct a sensitivity analysis using four alternative spatial ranges larger than the municipality for the computation of average neighbouring farm characteristics. ${ }^{5}$

To better capture the impact of neighbouring farm characteristics on farmer choice, we calculate the deviation from own farm characteristics. From this, we compute deviation from own farm size (area_mun_deviation), that is, the difference between average size in the municipality and own farm size, and use it as a proxy for deviation from the size of neighbouring farms. To control for heterogeneity in farm size within the municipality, we include Gini coefficients computed at the municipality level in the model specification. We also calculate the deviation from (per partner) agricultural profit (agri_profit_mun_deviation) and the deviation from the median age of farm holders (median_age_mun_deviation). In addition, we compute the share of neighbouring farms that specialise in production systems that use more land on average (highlanduse_mun_share) and the share of neighbouring corporate farms (corporate_mun_share) at the municipality level. Own farm characteristics are excluded from the calculation in order to avoid double counting. This also adds variation to the data because farms in the same municipality are then characterized by different neighbouring farm characteristics.

Regional farm characteristics $\left(\mathbf{q}_{i t-1}\right.$ variables in the model) are computed at the small agricultural region (SAR) level. SARs are geographical units that are defined as groups of municipalities with homogeneous agricultural systems and soil and climatic conditions. The mean size of a French SAR is 767 square kilometers, with a standard deviation of $722 \mathrm{~km}^{2}$. Based on the National Institute of Statistics and Economic Studies (INSEE) 2007 classification, there are 25 SARs in Brittany and their mean size is about 1,094 square kilometers, with a standard deviation of $914 \mathrm{~km}^{2}$. The average number of municipalities per SAR within the sample is 50 , with a standard deviation of 42 . The farm area, farm (per partner) agricultural profit, median age of farm holders, share of farms specialised in production systems that use more land and

\footnotetext{
${ }^{5}$ As one referee noted, the spatial scale of the land market on which farms may compete may actually be narrower (rather than larger) than the municipality. However, the empirical evidence reported by Latruffe and Piet (2014) as regards the fragmentation of farmland in Brittany would rather support that the imbrication of parcels is usually such that farms belonging to the same municipality are likely to share common bordering third plots, hence may be competitors, be their farmstead close or remote from each other inside the municipality. It is therefore also likely that the parcels of a farm whose farmstead is located near the border of a municipality, overlap on neighbouring municipalities, justifying the reported sensitivity analysis with respect to larger spatial scales.
} 
Table 1. Definition and descriptive statistics of explanatory variables $(\mathrm{n}=317,242)$.

\begin{tabular}{|c|c|c|c|c|c|}
\hline Variable & Code & Mean & St.Dev. & Min. & Max. \\
\hline \multicolumn{6}{|l|}{ Farm level } \\
\hline Total UAA (ha) & area & 48.70 & 55.04 & 0.00 & $8,420.67$ \\
\hline Per partner agricultural profit (1,000 Euros) & agri_profit & 10.68 & 12.39 & -313.92 & 465.72 \\
\hline Median age of the farm holders (years) & median_age & 48.31 & 9.11 & 18.50 & 99.00 \\
\hline Low-land-use farm dummy ( 1 if yes) & lowlanduse & 0.07 & 0.25 & 0 & 1 \\
\hline Middle-land-use farm dummy ( 1 if yes) & middlelanduse & 0.28 & 0.45 & 0 & 1 \\
\hline High-land-use farm dummy (1 if yes) & highlanduse & 0.65 & 0.48 & 0 & 1 \\
\hline Corporate farm dummy (1 if yes) & corporate & 0.46 & 0.50 & 0 & 1 \\
\hline \multicolumn{6}{|l|}{ Municipality level (mun) } \\
\hline Deviation from average farm size & area_mun_deviation & 0.00 & 55.42 & $-8,366.12$ & 642.69 \\
\hline Gini coefficient of land distribution & gini_mun & 0.41 & 0.08 & 0.01 & 0.89 \\
\hline Deviation from average agricultural profit & agri_profit_mun_deviation & 0.00 & 12.29 & -443.785 & 323.48 \\
\hline Deviation from average median age of farm holders & median_age_mun_deviation & 0.00 & 9.20 & -51.55 & 38.40 \\
\hline Share of high-land-use farms (\%) & highlanduse_mun_share & 64.98 & 17.03 & 0 & 100 \\
\hline Share of corporate farms (\%) & corporate_mun_share & 45.12 & 14.40 & 0 & 100 \\
\hline \multicolumn{6}{|l|}{ Small agricultural region level (sar) } \\
\hline Average farm size & average_sar_area & 48.70 & 7.60 & 13.93 & 68.18 \\
\hline Average per partner agricultural profit & average_sar_agri_profit & 10.68 & 2.20 & 6.03 & 29.35 \\
\hline Average median age of farm holders & average_sar_median_age & 48.31 & 1.04 & 44.31 & 50.97 \\
\hline Share of high-land-use farms (\%) & sar_highlanduse_share & 65.78 & 8.73 & 21.26 & 75.79 \\
\hline Share of corporate farms (\%) & sar_corporate_share & 46.03 & 8.26 & 24.44 & 66.67 \\
\hline \multicolumn{6}{|l|}{ Employment regional level } \\
\hline Unemployment rate (\%) & regional_unempl_rate & 6.89 & 1.13 & 3.70 & 9.40 \\
\hline
\end{tabular}

Note: Low-land-use are farm specialisations with an average farm size less than 20 hectares; middle-land-use are farm specialisations with an average farm size between 20 and 50 hectares; high-land-use are farm specialisations with an average farm size more than 50 hectares;

Source: MSA COTNS database, Brittany 2004-2014 - authors' calculations

corporate legal status variables are defined as the averages at the SAR level: average_sar_area, average_sar_agri_profit, average_sar_median_age, sar_highlanduse_share and sar_corporate_share. SAR level variables only take into account farms whose farmsteads are located in the same SAR. Farm characteristics at the SAR level may capture spatial correlations arising from unobserved spatially correlated regional characteristics. This may therefore allow for the effects of farm interactions that take place at the municipality level to be distinguished from such larger-scale spatial correlations.

Additionally, we use the rate of unemployment in the corresponding employment zone (regional_unempl_rate). According to INSEE, an employment zone is a geographical area that groups municipalities according to the areas in which most of the labour force lives and works. ${ }^{6}$

\footnotetext{
${ }^{6}$ More information on the employment zone division in France is available at https://www.insee.fr/en/ metadonnees/definition/c1361 (last accessed 20 August 2018).
} 
There exist 18 employment zones in Brittany. The unemployment rate in the employment zone captures the opportunities for off-farm activities and is thus assumed to have a positive effect on the probability of a farm remaining in farming. Finally, a time trend variable is introduced to capture the potential effects of, for example, technical changes in the sector that may influence farm survival.

Table 1 reports descriptive statistics for the variables chosen in the specification of the model. All explanatory variables are lagged by one year. Using lagged explanatory variables reduces potential endogeneity problems arising from the fact that exits from farming may influence average farm characteristics in municipalities. Indeed, while it is clear that exits from farming can contribute to increasing, for example, the average farm size in the municipality of interest, this should not influence the average farm size in the previous periods. As regards potential omitted variables in the specification of the model, we assume that the mixture modelling approach contributes to reducing omitted-variable problems since it controls for unobserved heterogeneity.

\section{Results}

The mixed probit model distinguishes between three optimal types of farms in the studied farm sample based on the information criteria reported in Table 2. Three was retained as the optimal number for two reasons: first, both the BIC and CAIC indicate that three is the optimal number of farm types; second, even if the AIC and AIC3 point to a higher optimal number of farm types, their values reveal that the improvement in these two criteria is relatively small when specifying more than three types of farms. This means that increasing the total number of homogeneous types in the sample increases the total number of parameters to be estimated considerably more than it does the representativeness of the data-generating process. For the sake of parsimony, a mixture of three types of farms is thus preferable for the analysis of farmers' decisions to remain in or exit from farming, assuming a heterogeneous population. ${ }^{7}$

\subsection{Benchmark: pooled probit}

We first present the results from a homogeneous pooled probit, which represents a naive estimation in which unobserved heterogeneity is not considered. The estimated parameters for the homogeneous model thus reflect the mean effect of a farm's own characteristics and of neighbou-

\footnotetext{
${ }^{7}$ Three is the optimal number of unobserved types based on the chosen information criteria, but it should be noted that this is only one option for the model specification. As one referee pointed out, there remains a certain degree of model uncertainty. In a Bayesian context, one could consider a model averaging approach that would enable accounting for different models with different numbers of endogenous types. We see the potential advantages of such an approach but leave its implementation in this context to future research.
} 
Table 2. Information criteria for the selection of optimal number of farm types.

\begin{tabular}{ccccccc}
\hline Groups & LL & Parameters & AIC & BIC & CAIC & AIC3 \\
\hline 1 & $-76,206$ & 24 & 152,460 & 152,716 & 152,740 & 152,484 \\
2 & $-73,857$ & 49 & 147,812 & 148,335 & 148,384 & 147,861 \\
3 & $-73,574$ & 74 & 147,296 & 148,085 & 148,159 & 147,370 \\
4 & $-73,471$ & 99 & 147,140 & 148,196 & 148,295 & 147,239 \\
5 & $-73,381$ & 124 & 147,010 & 148,333 & 148,457 & 147,134 \\
\hline
\end{tabular}

Source: MSA COTNS database, Brittany 2004-2014 - authors' calculations

ring farm characteristics on the probability of remaining in or exiting from farming, controlling for spatial correlations at the SAR level. The results from the pooled probit model reported in column 1 of Table 3 are consistent with our expectations. Overall, a positive correlation is observed between farm exit and farm size in terms of the total UAA, the agricultural profit, and the median age of farm holders. The results also confirm a non-linear effect of both total farm area and the median age of farm holders, as the coefficients associated with these squared variables are negative and statistically significant. ${ }^{8}$ The coefficient associated with the agricultural profit per partner is also positive, but interestingly, for farms close to retirement, the effect of profits is negative, ${ }^{9}$ suggesting that farmers are more likely to retire when farming activities are profitable. One explanation for this result could be that these farmers expect a significant retirement pension or that these farms are able to find successors or buyers more easily. The results also indicate that the probability of exiting from farming is lower for farms specialising in productions systems characterized by an average land use of between 20 and 50 hectares. The coefficient of the interaction term between farm size in terms of the total UAA and the dummy variable representing whether a farm specialises in a production system that uses more land than average is positive but not significant. The positive and significant coefficient of corporate farms confirms that corporate farms have a higher probability of remaining in business over the years.

Turning to the impacts of neighbouring farm characteristics, all of the coefficients for the variables computed at the municipality level are found to be insignificant except for the Gini coefficients and the deviation from the average age of neighbouring farm holders. In particular,

${ }^{8}$ It can be derived from the coefficients in Table 3 that the overall effect of farm size in terms of the total UAA becomes negative above around 6,155 (0.0027/3.84e-07) hectares and a median farm holder age of above 55 $(0.0165 / 0.0003)$ years. This means that both non-linear effects are positive over the entire sample for farm size and most of the sample for age.

${ }^{9}$ We find a negative effect of the interaction term between profits and retirement. Since the effect of the interaction term is larger in absolute terms (-0.0182) than the coefficient for profits $(0.0027)$, the overall effect of profit becomes negative for those farmers who are close to retirement. 
the pooled probit does not identify any link between a deviation of the average neighbouring farm size from own size and the probability of remaining in or exiting from farming. However, the effect of the Gini coefficient is significantly different from zero, suggesting that the probability of exiting increases with farm size heterogeneity within the municipality. This result is consistent with previous studies that have found that structural change accelerates with increased heterogeneity in farm size (see for example Zimmermann and Heckelei (2012)). The probability of surviving is higher in SARs with higher average ages of farm holders, higher average agricultural profits, as well as in SARs with a greater percentage of farms specialising in production systems that use greater amounts of land.

As expected, the unemployment rate is found to be positively correlated with farm survival. Farmers may be forced to stay in business if they do not anticipate having alternative local job opportunities. The coefficient of the time trend is also positive, which indicates that the probability of exiting decreases over time for the period considered (2004-2014), holding everything else constant.

\subsection{Farm types from the mixed probit model}

The estimated parameters for each farm types are presented in columns 2, 3 and 4 of Table 3. The mixture model identifies impacts that are specific to the endogenously-determined homogeneous farm types. The three types of farms differ especially with respect to the effect of neighbouring farm size. The first and second farm types in the mixture model are characterised by a significant positive and negative correlation between neighbouring farm size and the probability of remaining in farming for two consecutive years, respectively. For the third type of farm, the correlation is considerably smaller and not significant. A negative effect of neighbouring farm size on the probability of remaining in farming is found for the majority of farms (about $52 \%$, type 2) while the positive correlation is observed only for about $19 \%$ of farms (type 1). Referring to the discussion in Section 2, one possible explanation for this difference in correlations could be that the first two farm types could consist mostly of business-oriented farms where farm holders are mainly motivated by profit maximisation. The resulting negative correlation between neighbouring farm size and the probability of remaining in farming for type 2 farms may indicate that farms of this type tend to be competitors for land, while the opposite effect for type 1 farms may arise from positive spillovers of new technology adoption. 
Table 3. Estimated parameters for both the pooled and the mixture of probit models.

\begin{tabular}{|c|c|c|c|c|c|c|c|c|c|c|}
\hline \multirow{3}{*}{ Variable code } & \multirow{2}{*}{\multicolumn{2}{|c|}{$\begin{array}{l}\text { Pooled } \\
\text { Probit }\end{array}$}} & \multicolumn{8}{|c|}{ Mixed Probit } \\
\hline & & & \multicolumn{2}{|c|}{ Type 1} & \multicolumn{2}{|c|}{ Type 2} & \multicolumn{2}{|c|}{ Type 3} & \multicolumn{2}{|c|}{ Aggregate } \\
\hline & Estimate & Std. Err. & Estimate & Std. Err. & Estimate & Std. Err. & Estimate & Std. Err. & Estimate & Std. Err. \\
\hline intercept & -0.1305 & $(0.3223)$ & -0.0830 & $(0.4415)$ & $-1.1892^{* *}$ & $(0.3696)$ & $-56.5258^{* * *}$ & $(1.2145)$ & $-17.0289 * * *$ & $(0.4101)$ \\
\hline time_trend & $0.0100^{* * *}$ & $(0.0030)$ & $-0.0252^{* * *}$ & $(0.0041)$ & $-0.0242^{* * *}$ & $(0.0035)$ & $0.1128^{* * *}$ & $(0.0094)$ & $0.0154^{* * *}$ & $(0.0033)$ \\
\hline area & $0.0028^{* * *}$ & $(0.0004)$ & $-0.0031^{* * *}$ & $(0.0006)$ & $0.0057^{* * *}$ & $(0.0004)$ & $0.0026^{*}$ & $(0.0012)$ & $0.0031^{* * *}$ & $(0.0004)$ \\
\hline area_square & $-3.84 \mathrm{e}-07^{* * *}$ & $(2.32 \mathrm{e}-08)$ & $4.78 \mathrm{e}-06^{* * *}$ & $(5.68 \mathrm{e}-07)$ & $-7.49 \mathrm{e}-07^{* * *}$ & $(2.27 \mathrm{e}-08)$ & $3.79 \mathrm{e}-05^{* * *}$ & $(6.01 \mathrm{e}-06)$ & $1.15 \mathrm{e}-05^{* * *}$ & $(1.74 \mathrm{e}-06)$ \\
\hline agri_profit & $0.0027^{*}$ & $(0.0012)$ & $-0.0377^{* * *}$ & $(0.0017)$ & $0.0059^{* * *}$ & $(0.0014)$ & $0.0587^{* * *}$ & $(0.0058)$ & $0.0130^{* * *}$ & $(0.0019)$ \\
\hline median_age & $0.0165^{* * *}$ & $(0.0030)$ & $-0.0232^{* * *}$ & $(0.0042)$ & $0.0124^{* * *}$ & $(0.0034)$ & $2.9882^{* * *}$ & $(0.0311)$ & $0.86867^{* * *}$ & $(0.0092)$ \\
\hline median_age_square & $-0.0003^{* * *}$ & $(2.24 \mathrm{e}-05)$ & $2.08 \mathrm{e}-05$ & $(3.14 \mathrm{e}-05)$ & $-0.0001^{* * *}$ & $(2.53 \mathrm{e}-05)$ & $-0.0368^{* * *}$ & $(0.0003)$ & $-0.0107^{* * *}$ & $(0.0001)$ \\
\hline agri_profit_X_retirement & $-0.0182^{* * *}$ & $(0.0006)$ & $-0.0286^{* * *}$ & $(0.0008)$ & $-0.0158^{* * *}$ & $(0.0006)$ & $-0.0482^{* * *}$ & $(0.0045)$ & $-0.0276^{* * *}$ & $(0.0014)$ \\
\hline lowlanduse & 0.0177 & $(0.0149)$ & $0.5491^{* * *}$ & $(0.0265)$ & $-0.0438^{*}$ & $(0.0193)$ & $0.2852^{* * *}$ & $(0.0550)$ & $0.1631^{* * *}$ & $(0.0195)$ \\
\hline middlelanduse & $0.0855^{* * *}$ & $(0.0132)$ & $0.2330^{* * *}$ & $(0.0171)$ & $0.0662^{* * *}$ & $(0.0141)$ & $0.0733^{*}$ & $(0.0363)$ & $0.0996^{* * *}$ & $(0.0132)$ \\
\hline highlanduse____area & 0.0001 & $(0.0003)$ & 0.0003 & $(0.0004)$ & -0.0003 & $(0.0003)$ & -0.0006 & $(0.0009)$ & -0.0003 & $(0.0003)$ \\
\hline corporate & $0.3228^{* * *}$ & $(0.0091)$ & $1.0149^{* * *}$ & $(0.0129)$ & $0.3125^{* * *}$ & $(0.0100)$ & 0.0204 & $(0.0299)$ & $0.3598^{* * *}$ & $(0.0104)$ \\
\hline area_mun_deviation & -0.0003 & $(0.0002)$ & $0.0037^{* * *}$ & $(0.0005)$ & $-0.0011^{* * *}$ & $(0.0003)$ & 0.0010 & $(0.0006)$ & 0.0004 & $(0.0003)$ \\
\hline area_mun_gini & $-0.1266^{*}$ & $(0.0536)$ & $0.6147^{* * *}$ & $(0.0727)$ & $-0.2921^{* * *}$ & $(0.0612)$ & -0.3115 & $(0.1651)$ & $-0.1273^{*}$ & $(0.0592)$ \\
\hline agri_profit_mun_deviation & 0.0014 & $(0.0012)$ & $0.0061^{* * *}$ & $(0.0016)$ & 0.0012 & $(0.0014)$ & $0.0106^{* *}$ & $(0.0037)$ & $0.0048^{* * *}$ & $(0.0013)$ \\
\hline median_age_mun_deviation & $0.0043^{*}$ & $(0.0018)$ & 0.0018 & $(0.0024)$ & 0.0039 & $(0.0021)$ & $0.0210^{* * *}$ & $(0.0056)$ & $0.0085^{* * *}$ & $(0.0020)$ \\
\hline highlanduse_mun_share & -0.0190 & $(0.0302)$ & $-0.1516^{* * *}$ & $(0.0410)$ & -0.0307 & $(0.0350)$ & 0.0239 & $(0.0931)$ & -0.0375 & $(0.0335)$ \\
\hline corporate_mun_share & -0.0550 & $(0.0362)$ & $-0.2776^{* * *}$ & $(0.0492)$ & -0.0248 & $(0.0415)$ & -0.1418 & $(0.1105)$ & $-0.1062^{* *}$ & $(0.0398)$ \\
\hline average_sar_area & 0.0010 & $(0.0007)$ & $0.0044^{* * *}$ & $(0.0010)$ & $0.0021^{* *}$ & $(0.0008)$ & $-0.0067^{* *}$ & $(0.0022)$ & $2.39 \mathrm{e}-06$ & $(0.0008)$ \\
\hline average_sar_agri_profit & $0.0108^{* * *}$ & $(0.0025)$ & $0.0518^{* * *}$ & $(0.0034)$ & $0.0127^{* * *}$ & $(0.0029)$ & $0.0157^{*}$ & $(0.0080)$ & $0.0209^{* * *}$ & $(0.0028)$ \\
\hline average_sar_median_age & $0.0196^{* *}$ & $(0.0066)$ & $0.0502^{* * *}$ & $(0.0090)$ & $0.0318^{* * *}$ & $(0.0076)$ & $0.1589^{* * *}$ & $(0.0209)$ & $0.0721^{* * *}$ & $(0.0074)$ \\
\hline sar_highlanduse_share & $0.2623^{* * *}$ & $(0.0601)$ & $0.4265^{* * *}$ & $(0.0787)$ & $0.2799 * * *$ & $(0.0699)$ & $0.6910^{* * *}$ & $(0.1845)$ & $0.4267^{* * *}$ & $(0.0664)$ \\
\hline sar_corporate_share & -0.1154 & $(0.0807)$ & $-0.5772^{* * *}$ & $(0.1090)$ & -0.0494 & $(0.0922)$ & $-0.5667^{*}$ & $(0.2536)$ & $-0.2987^{* * *}$ & $(0.0902)$ \\
\hline regional_unempl_rate & $0.0118^{* * *}$ & $(0.0035)$ & 0.0067 & $(0.0047)$ & $0.0181^{* * *}$ & $(0.0040)$ & $0.0883^{* * *}$ & $(0.0107)$ & $0.0363^{* * *}$ & $(0.0038)$ \\
\hline Type shares & & & $18,77 \%$ & & $52,24 \%$ & & $28,99 \%$ & & $100 \%$ & \\
\hline Number of observations & 316,995 & & & & & & & & 316,995 & \\
\hline Log pseudo-likelihood & $-76,206$ & & & & & & & & $-73,574$ & \\
\hline
\end{tabular}

Note: area_mun_deviation, median_age_mun_deviation and agri_profit_mun_deviation are deviations from own farm characteristics and highlanduse_mun_share and corporate_mun_share are

neighbouring farm shares computed at the municipality level; average_sar_area, average_sar_median_age, sar_highlanduse_share and sar_corporate_share are averages and shares computed at the SAR level; *,** and ${ }^{* * *}$ indicate significance at $5 \%, 1 \%$ and $0.1 \%$ levels, respectively.

Source: MSA COTNS database, Brittany 2004-2014 - authors' calculations 
Contrary to the first two farm types, the correlation between neighbouring farm size and the probability of surviving is highly non-significant for type 3 farms, which account for about $29 \%$ of farms in the sample. Referring again to the discussion in Section 2, this third, initially unanticipated, type of farm could represent farmers who are most motivated by non-pecuniary considerations. It could also represent business-oriented farms that have already reached their optimal economic size. The probability of remaining in or exiting from farming for such farms may therefore be independent of the size of neighbouring farms. 'Ceteris paribus', the probability of remaining in farming increases for type 3 farms over time, as the coefficient of the trend time is positive, while the inverse is observed for the other types of farms. An explanation for this result could be that the larger the neighbouring farms and the higher the competition for land, then the more difficult it becomes for farms to innovate since the adoption of new technology generally requires more land. Therefore, farmers that are primarily motivated by profit maximisation are more likely to close their business than farmers motivated primarily by non-pecuniary concerns.

Figure 1 reports the probability that an average farm remains active from one year to the next with respect to the difference between own-farm size and the average farm size calculated at the municipality level. The figure shows that, overall, the probability of surviving is lower for type 2 farms, which could represent highly competitive farms, and that this probability decreases when neighbouring farm size increases. The opposite effect is observed for type 1 farms that may benefit from positive spillovers of new technology adoption. Figure 1 also shows that the probability of surviving is higher and does not vary with the neighbouring farm size for type 3 farms, i.e. those farms that may have mainly non-pecuniary motives or that have already reached their optimal size. Since we also control for observed farm heterogeneity in the mixed probit model, it appears that the unobserved farm types are not correlated with the observed farm characteristics included in the model. ${ }^{10}$ Even if small differences in the mean values of some farm characteristics such as farm size and share of corporate farms do exist across unobserved farm types, their standard deviations are very large, meaning that these characteristics are not differently distributed across the endogenously identified farm types. This suggests that the different types of correlations demonstrated by the mixture model, which may capture farm interactions on the real estate market, do pertain to unobserved heterogeneity that is not fully captured by the farm characteristics included in the model specification.

\subsection{Impact of farm characteristics by type membership}

The impacts of own farm and farmer characteristics on the probability of remaining in or exiting from farming vary according to farm type. As the general impacts of the explanatory variables

\footnotetext{
${ }^{10}$ Descriptive statistics of observed characteristics by farm type endogenously identified by the mixed probit model are reported in the appendix.
} Agricultural Economics, 46 (2), 237-266. , DOI : 10.1093/erae/jby029 

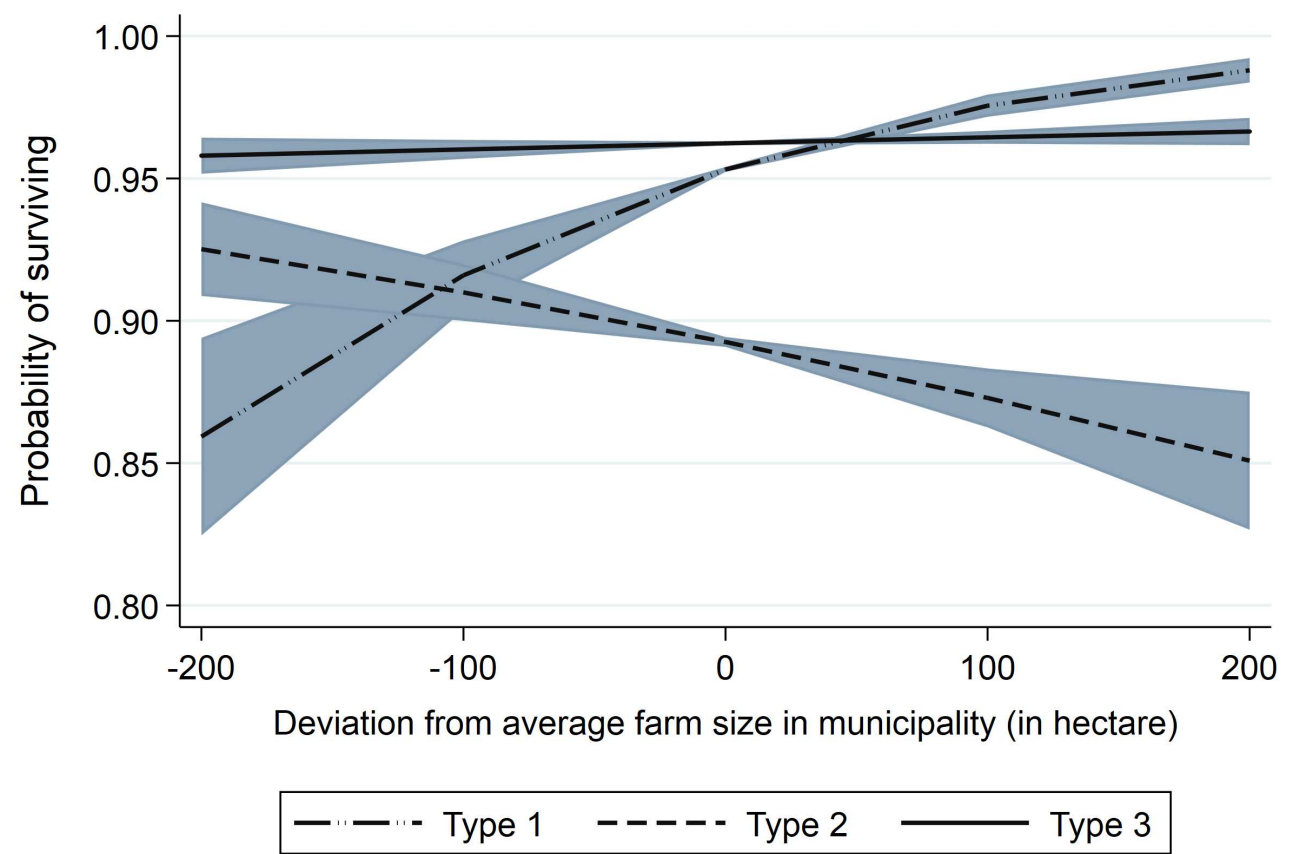

Fig. 1. Predicted probability of farm survival for varying levels of average neighbouring farm size (at the municipality level) by unobserved farm type.

Note: Predicted probabilities are computed with $95 \%$ confidence intervals at the average values of the other explanatory variables.

Source: MSA COTNS database, Brittany 2004-2014 - authors' calculations

have already been presented in Section 6.1, only several results of interest from the mixture model will be discussed here. The impact of own farm size on the probability of remaining in farming for two consecutive years is positive overall for type 2 and 3 farms and negative for type 1 farms, but these effects are rather small, especially for types 3 farms (see Figure 2). An explanation for this could be that the positive effect may result from the fact that larger farms are in a better position to compete for land, while smaller farms are more likely to benefit from positive spill-overs from new technology adoption by larger farms. Survival probabilities are rather large for type 1 and 2 farms and change with the age of the farm holder only to a limited extent. Whereas increasing farmer age corresponds to a slight decrease in survival probability for type 1 farms, an opposite - but again limited - effect is observed for type 2 farms (see Figure 3). One possible explanation could be that succession is better planned among type 2 farms compared to type 1 farms. The process of determining the succession of farms may be influenced by a variety of factors, especially those related to a farmers motivations as well 


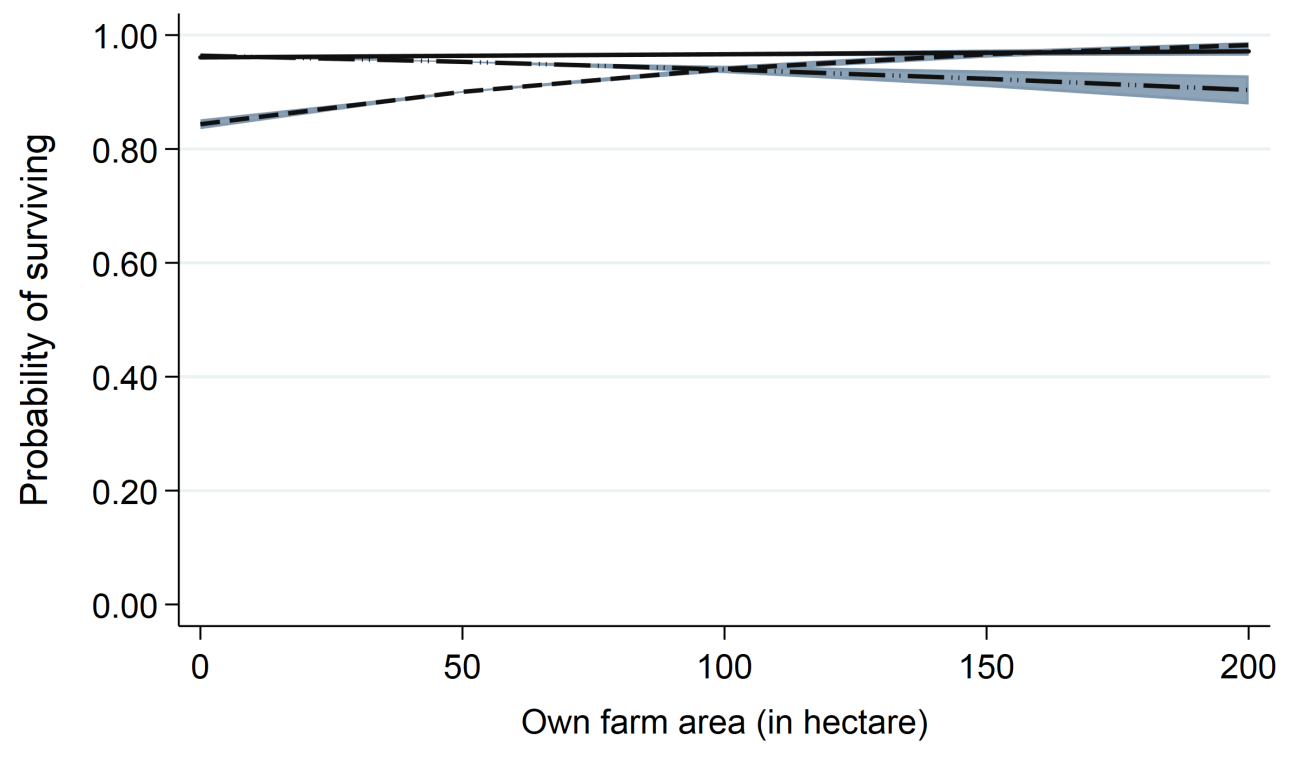

-"-"- Type 1 ----- Type 2 Type 3

Fig. 2. Predicted probability of farm survival for varying levels of own farm size by unobserved farm type.

Note: Predicted probabilities are computed with $95 \%$ confidence intervals at the average values of the other explanatory variables.

Source: MSA COTNS database, Brittany 2004-2014 - authors' calculations

as the characteristics of potential successors (Kimhi and Lopez, 1999; Glauben et al., 2009). Most strikingly, type 3 farms exhibit a very low survival probability for young farmers, which increases rapidly with farmer age. This could be explained by the fact that young farmers may have significantly better off-farm job opportunities relative to older farmers. The non-pecuniary motives that may be associated with type 3 farms could also explain the higher survival rate of farms owned by farm holders who are closer to retirement.

The agricultural profit of the farm has a positive effect on the probability of remaining in farming only for type 2 and 3 farms. While the negative impact of agricultural profit the survival probability for type 1 farms is more difficult to interpret, the positive effect for the other farm types confirms that farms are less likely to exit when farming activities are profitable. This probability generally decreases as farmers approach retirement. Results also indicate that farms specialising in production systems that use lower amounts of land have a higher probability of remaining in farming whatever their type. However, type 2 farms have a lower survival 


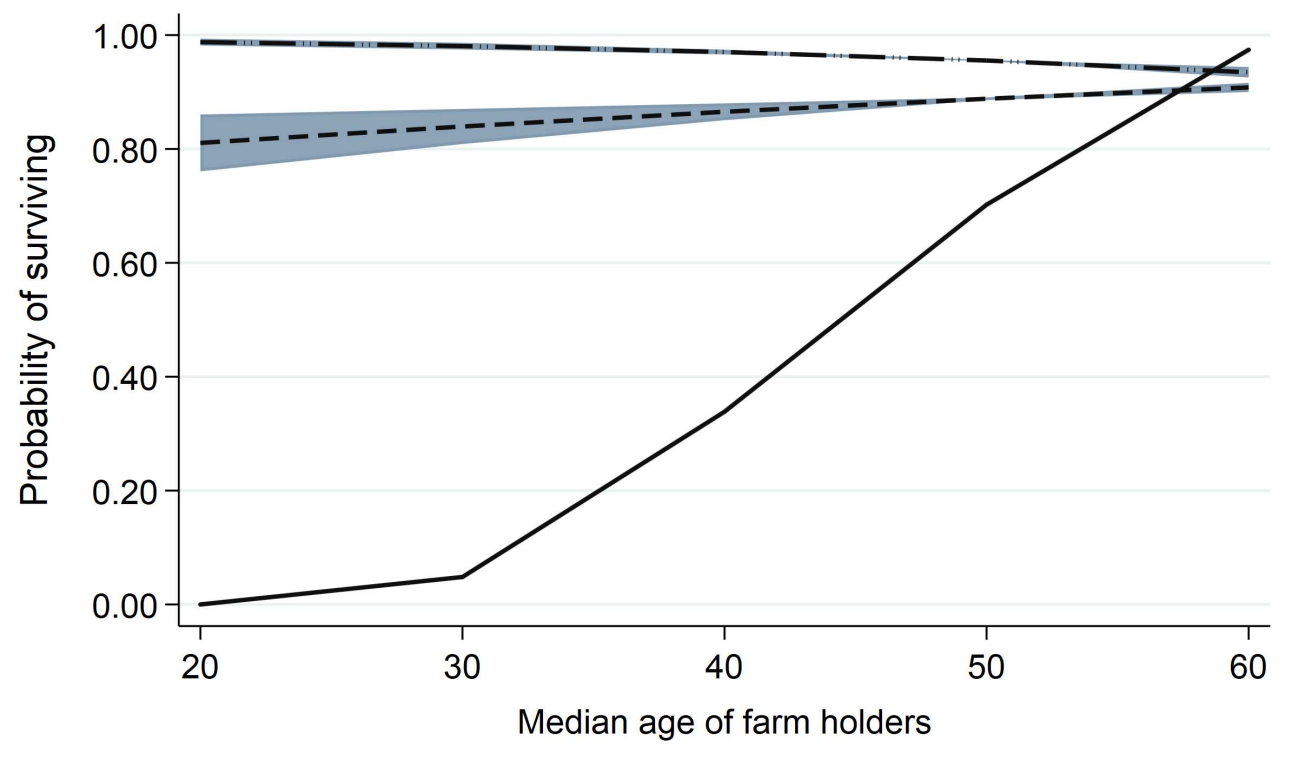

-"-"- Type 1 ----- Type 2 Type 3

Fig. 3. Predicted probability of farm survival for varying levels of median farm holder age by unobserved farm type.

Note: Predicted probabilities are computed with $95 \%$ confidence intervals at the average values of the other explanatory variables.

Source: MSA COTNS database, Brittany 2004-2014 - authors' calculations

probability when they are specialised in production systems with an average farm size of less than 20 hectares in terms of total UAA. This suggests that the competitiveness and the sustainability of type 2 farms depend on an optimal size that lies between 20 and 50 hectares in Brittany. The results also indicate that legal status is relevant only for type 1 and type 2 farms. Because these farm types are likely to be more motivated by profit maximisation, operating under a corporate legal status may provide easier access to the capital necessary for technological innovation or farm expansion.

In order to allow for a direct comparison with the results of the benchmark pooled probit model, results from the mixture model may be aggregated at the population level using the estimated parameters for each farm type and their respective shares in the population. The results reported in column 5 of Table 3 indicate that the aggregated parameters from the mixed probit differ from those obtained with the pooled probit. Even if the same signs are observed for almost all parameters, the coefficient values, as well as the level of significance, are different 
Table 4. Classification tables for (a) the pooled probit model and (b) the mixed probit model.

\begin{tabular}{ccccc}
\hline & & \multicolumn{2}{c}{ Observed } & \multirow{2}{*}{ Total } \\
\cline { 3 - 4 } & & Survivals & Exits & \\
\hline \multirow{2}{*}{ Predicted } & Survivals & 294,054 & 22,847 & 316,901 \\
Total & Exits & 76 & 18 & 94 \\
& & 294,130 & 22,865 & 316,995 \\
\hline \multirow{2}{*}{ Correctly classified } & & & & $92.77 \%$ \\
\hline
\end{tabular}

a) Pooled probit

\begin{tabular}{ccccc}
\hline \multirow{2}{*}{ Predicted } & & \multicolumn{2}{c}{ Observed } & \\
\cline { 3 - 4 } & & Survivals & Exits & Total \\
\hline \multirow{2}{*}{ Survivals } & 293,948 & 19,323 & 313,271 \\
& Exits & 182 & 3,542 & 3,724 \\
& Total & 294,130 & 22,865 & 316,995 \\
\hline \multirow{2}{*}{ Correctly classified } & & & & $93.85 \%$ \\
\hline
\end{tabular}

b) Mixed probit

\begin{abstract}
Note: observations are assigned as surviving or exiting according to the 0.5 -cutoff rule : observations whose predicted survival probability is above 0.5 are classified as surviving and otherwise exiting.
\end{abstract}

Source: MSA COTNS database, Brittany 2004-2014 - authors' calculations

for many parameters, showing that accounting for unobserved heterogeneity is important also in order to derive sound aggregate results. The correlation between neighbouring farm size and the probability of survival is negative but insignificant, as in the case of the homogeneous pooled probit where unobserved heterogeneity is not considered. The opposite and insignificant correlations obtained for the three farm types, however, are now able to offer an explanation for the insignificant effect of neighbouring farm size at the aggregate level. The insignificant coefficient obtained at the aggregate level does not imply that neighbouring farm size has no effect on farmer behaviours, but rather that the impact differs across the farm types such that they cancel each other out among the entire farm population in Brittany. The mixture model thus provides an opportunity to more comprehensively analyse the impact of neighbouring farm size on exit decisions by providing a more accurate portrayal of the differences that exist in the way that farmers interact in the real estate market.

Finally, in addition to identifying the differing impacts of neighbouring farm size that are not revealed in the pooled probit model, the mixture probit model is also more accurate especially in predicting exits from farming: as Table 4 shows, the share of total correct predictions is $93.85 \%$ for the mixed probit while it is $92.77 \%$ for the pooled probit. This result confirms that 
the mixture model outperforms the homogeneous model in representing the data-generating process.

\subsection{Sensitivity analysis}

Since farms may compete for land in neighbouring municipalities, we conduct a sensitivity analysis by estimating the mixture model using deviation of the average neighbouring farm characteristics from own characteristics computed at different spatial scales, that is, for different definitions of the spatial weighting matrix $(\mathbf{W})$ in the computation of the vector of explanatory variables $(\mathbf{z})$. First, we include in the calculation of the average neighbouring farm characteristics all farms whose farmstead is located in municipalities that are directly adjacent to the municipality of the farm under consideration. This leads to an average of 5.5 neighbouring municipalities with a minimum of 1 and a maximum of 15 . In a second trial, we repeat the analysis considering the distance between municipality centroids. In this case, it appears that a distance of 6.5 kilometres as the crow flies between two municipalities yields an average of 5.7 neighbouring municipalities with a minimum of 1 and a maximum of 14, indicating comparability with the results obtained from the first order contiguity matrices. This distance, over which farms are thus assumed to compete for land, is all-the-more appropriate given that Latruffe and Piet (2014) show that the maximum average distance of a hectare in Brittany is about 6.8 kilometres as the crow flies. In a third trial, we compute average neighbouring farm characteristics using the distance in kilometers, and in a fourth, we use the total road travel time between two municipalities. The neighbouring municipality matrices using these two types of distances are derived from the Odomatrix software that enables the computing of different types of distances between the French municipalities (Hilal, 2010). ${ }^{11}$ For comparisons purposes, we again use a distance of 8 kilometers and 10 minutes travel time to identify neighbouring municipalities and to compute average neighbouring farm characteristics. The resulting average number of neighbouring municipalities are 5.6 and 5.5 for the third and fourth trials, respectively, with a minimum of 1 and a maximum of 14 for both types of distances. It should be noted that even though the different definitions for the spatial weighting matrix (W) were chosen so as to obtain similar average, minimum and maximum numbers of neighbours, each may lead to different neighbourhood subsets for specific municipalities.

The results using the four alternative spatial scales larger than the municipality lead to the same conclusion: that three types of farms exist in Brittany, and that these types are distin-

\footnotetext{
${ }^{11}$ The Odomatrix integrates a codified road database made up of layers of geographic information describing the road network and the geographical environment. The calculation of the distance between municipalities thus takes into account the characteristics of the geographical environment as well as the effects of sinuosity (road nodes, traffic speed, ...). See Hilal (2010) for more details about the Odomatrix software.
} 
guished by different correlations between neighbouring farm size and their survival probability. The results of the sensitivity analysis are reported in the appendix. Very similar proportions are obtained for each farm type identified by the mixture model in all of the iterations of the sensitivity analysis. The precision of the parameter of interest (neighbouring farm size) tends to decrease with the size of the geographical spread used for the calculation of the average neighbouring farm characteristics. However, the effect of the explanatory variables are quite similar across all estimations and the farm type considered, even though the coefficients and their level of significance occasionally differ.

Finally, a caveat to be discussed is the implication of using average farm size at the municipality level in order to capture the impact of neighbouring farm size. This may indeed introduce some bias in the estimation of the parameters since the same weight is considered for all of the observations in the same municipality. The sensitivity analysis we performed using larger spatial scales than the municipality led to the same three types of farms identified by the mixture model and a similar distribution of farm types in all alternative specifications. The precision of the parameters, however, tends to decrease when using a wider geographical spread to calculate average neighbouring farm characteristics. Based on this, it is plausible that a more appropriate definition of the relevant geographic market (specifically using the exact location of farms) would improve the precision of the estimates, but it is unlikely to change the main conclusions of this study.

\section{Concluding remarks}

The analysis presented in this paper illustrates the importance of accounting for unobserved heterogeneity in spatial interactions between farms when analysing the decisions of farmers to remain in or exit from farming. This was made possible by the mixture modelling approach that endogenously groups farms into specific homogeneous types. This approach allows for farms of different types to be characterised by different impacts of neighbouring farm size on their likelihood of remaining in or exiting from farming. The model is applied to a panel of French farms located in Brittany and indeed demonstrates that there exist different types of correlations between neighbouring farm size and survival probability, which could be due to the interactions between farms on the real estate market. A negative correlation between neighbouring farm size and survival probability is estimated for the majority of farms, but a positive correlation is also obtained for a significant proportion of farms. These two opposite effects could respectively originate from competition for land and spillover from new technology adoption. However, for a significant proportion of farms in Brittany, the correlation between neighbouring farm size and the probability of remaining in farming over time is not significant. This may reflect the behaviour of farmers who have a limited interest in enlarging the size of their farm, possibly 
due to the presence of non-pecuniary motivations or having already achieved an economicallyoptimal farm size. Our results indicate that spatial interactions between farms on the real estate market may be driven by very different motivations.

From a methodological point of view, this analysis demonstrates the usefulness of the mixed modelling approach. The more flexible parametrization compared to a pooled (homogeneous) model not only increases model fit, but provides a more accurate picture of the heterogeneous behaviour of farmers. Even if one is only interested in the aggregate impacts of certain determinants, applying a mixed modelling approach could be still prove useful, as the current analysis shows how aggregate results across groups under a mixture modelling framework also differ from the results obtained when using an average modelling approach. More importantly, however, is the fact that average (pooled) modelling may actually mask the effect of certain determinants of behaviour among different farm groups behind insignificant coefficients, which increases the chances of drawing incorrect policy conclusions.

Although some additional discussion could be undertaken regarding potential sources of heterogeneity in spatial interactions between farms, the nature of 'unobserved' heterogeneity is that the data itself cannot be used for confirming hypotheses, which could be considered to be a limitation compared to the alternative of simply having more ideal data available. Future studies would benefit from including data on the subsidies received by the farms and their neighbours since such subsidies may have a significant impact on farmer decisions to remain in or exit from farming, as has been demonstrated by previous work (see Storm et al. (2015) for a recent example). Even without the inclusion of this policy-relevant variable, however, are our results are nevertheless important for policy analyses. Storm et al. (2015) find that neighbour effects are important for a policy assessment due to interactions between farms, particularly on the real estate market. Our findings indicate that the importance of competition on the real estate market and hence the effects of neighbouring farm characteristics, is quite heterogeneous in the population. Thus, mean neighbour effects, as studied in Storm et al. (2015), can in fact reflect significant underlying heterogeneity among different groups of farms. It will be important to take this heterogeneity into account for future policy analyses, and the mixture modelling approach we develop here can provide the means to do so.

\section{References}

AGRESTE-Bretagne (2017). Les marchés fonciers de l'espace rural Breton. Des disparités selon les territoires et le profil de l'acquéreur. Février 2017- 2, 4 pages.

Andrews, R. L. and Currim, I. S. (2003). Retention of latent segments in regression-based marketing models. International Journal of Research in Marketing 20: 315-321. 
Aubert, M. and Perrier-Cornet, P. (2009). Is there a future for small farms in developed countries? Evidence from the French case. Agricultural Economics 40: 797-806.

Bollman, R. D., Whitener, L. A. and Tung, F. L. (1995). Trends and patterns of agricultural structural change: a Canada-US comparison. Canadian Journal of Agricultural Economics/Revue Canadienne d'Agroéconomie 43: 15-28.

Bowman, M. S. and Zilberman, D. (2013). Economic factors affecting diversified farming systems. Ecology and Society 18: 33.

Breustedt, G. and Glauben, T. (2007). Driving forces behind exiting from farming in Western Europe. Journal of Agricultural Economics 58: 115-127.

Case, A. (1992). Neighborhood influence and technological change. Regional Science and Urban Economics 22: 491-508.

Conradt, S., Bokusheva, R., Finger, R., Kussaiynov, T. et al. (2014). Yield trend estimation in the presence of farm heterogeneity and non-linear technological change. Quarterly Journal of International Agriculture 53: 121-140.

Daniels, T. L. (1986). Hobby farming in america: rural development or threat to commercial agriculture? Journal of Rural Studies 2: 31-40.

Dempster, A. P., Laird, N. M. and Rubin, D. B. (1977). Maximum likelihood from incomplete data via the em algorithm. Journal of the Royal Statistical Society. Series B (Methodological) 39: $1-38$.

Dong, F., Hennessy, D. A. and Jensen, H. H. (2010). Contract and exit decisions in finisher hog production. American Journal of Agricultural Economics 92: 667-684.

Eastwood, R., Lipton, M. and Newell, A. (2010). Farm size. Handbook of agricultural economics 4: $3323-3397$.

Gaté, R. and Latruffe, L. (2016). Difficultés rencontrées lors de la transmission d'exploitations agricoles. Le cas de la Bretagne. Économie rurale 1: 5-24.

Gibbons, S. and Overman, H. G. (2012). Mostly pointless spatial econometrics? Journal of Regional Science 52: 172-191.

Glauben, T., Petrick, M., Tietje, H. and Weiss, C. (2009). Probability and timing of succession or closure in family firms: a switching regression analysis of farm households in Germany. Applied Economics 41: 45-54. 
Goddard, E., Weersink, A., Chen, K. and Turvey, C. G. (1993). Economics of structural change in agriculture. Canadian Journal of Agricultural Economics/Revue Canadienne d'Agroéconomie 41: $475-489$.

Greene, W. H. (2012). Econometric analysis (International edition). Pearson, 7th ed.

Hallam, A. (1991). Economies of size and scale in agriculture: an interpretive review of empirical measurement. Review of Agricultural Economics 13: 155-172.

Happe, K., Kellermann, K. and Balmann, A. (2006). Agent-based analysis of agricultural policies: an illustration of the agricultural policy simulator AgriPoliS, its adaptation and behavior. Ecology and Society 11: 49.

Harrington, D. H. and Reinsel, R. D. (1995). A synthesis of forces driving structural change. Canadian Journal of Agricultural Economics/Revue Canadienne d'Agroéconomie 43: 3-14.

Hess, S., Bierlaire, M. and Polak, J. (2007). A systematic comparison of continuous and discrete mixture models. European Transport 37: 35-61.

Hilal, M. (2010). Odomatrix. Calcul de distances routiéres intercommunales. Cahier des Techniques de lINRA. Numéro Spécial: méthodes et outils de traitement des données en sciences sociales. Retours dexpériences: pp. 41-63.

Holloway, G., Lacombe, D. and LeSage, J. P. (2007). Spatial econometric issues for bio-economic and land-use modelling. Journal of Agricultural Economics 58: 549-588.

Holloway, G., Shankar, B. and Rahmanb, S. (2002). Bayesian spatial probit estimation: a primer and an application to HYV rice adoption. Agricultural Economics 27: 383-402.

Holloway, L. (2002). Smallholding, hobby-farming, and commercial farming: ethical identities and the production of farming spaces. Environment and Planning A 34: 2055-2070.

Howley, P. (2015). The happy farmer: The effect of nonpecuniary benefits on behavior. American Journal of Agricultural Economics 97: 1072 -1086.

Howley, P., Dillon, E. and Hennessy, T. (2014). It's not all about the money: understanding farmers' labor allocation choices. Agriculture and Human Values 31: 261-271.

Jackson-Smith, D. B. (1999). Understanding the microdynamics of farm structural change: Entry, exit, and restructuring among Wisconsin family farmers in the 1980s. Rural Sociology 64: 66-91.

Kimhi, A. and Lopez, R. (1999). A note on farmers' retirement and succession considerations: Evidence from a household survey. Journal of Agricultural Economics 50: 154-162. 
Kyriazidou, E. (1997). Estimation of a panel data sample selection model. Econometrica 65: $1335-1364$.

Landi, C., Stefani, G., Rocchi, B., Lombardi, G. V. and Giampaolo, S. (2016). Regional differentiation and farm exit: a hierarchical model for Tuscany. Journal of Agricultural Economics 67: $208-230$.

Läpple, D., Holloway, G., Lacombe, D. J. and O'Donoghue, C. (2017). Sustainable technology adoption: a spatial analysis of the Irish dairy sector. European Review of Agricultural Economics 44: 810-835.

Latruffe, L. and Piet, L. (2014). Does land fragmentation affect farm performance? A case study from Brittany, France. Agricultural Systems 129: 68-80.

Maybery, D., Crase, L. and Gullifer, C. (2005). Categorising farming values as economic, conservation and lifestyle. Journal of Economic Psychology 26: 59 - 72.

McLachlan, G. and Krishnan, T. (2007). The EM algorithm and extensions, 382. John Wiley $\&$ Sons.

McLachlan, G. and Peel, D. (2004). Finite mixture models. John Wiley \& Sons.

Mzoughi, N. (2011). Farmers adoption of integrated crop protection and organic farming: Do moral and social concerns matter? Ecological Economics 70: 1536-1545.

Pennings, J. M. and Garcia, P. (2004). Hedging behavior in small and medium-sized enterprises: the role of unobserved heterogeneity. Journal of Banking 85 Finance 28: 951-978.

Storm, H. and Heckelei, T. (2018). Reducing omitted-variable bias in spatial-interaction models by considering multiple neighbourhoods. Spatial Economic Analysis doi:DOI:10.1080/ 17421772.2018 .1468571

Storm, H., Mittenzwei, K. and Heckelei, T. (2015). Direct payments, spatial competition, and farm survival in Norway. American Journal of Agricultural Economics 97: 1192-1205.

Temesgen, C. J. (2014). Analysis of localized farmland sales market in France. In Temesgen, C. J., Understanding price formation in french farmland markets. Ph.D Dissertation, Chap. 4, pp. $77-129$.

Trujillo-Barrera, A., Pennings, J. M. E. and Hofenk, D. (2016). Understanding producers' motives for adopting sustainable practices: the role of expected rewards, risk perception and risk tolerance. European Review of Agricultural Economics 43: 359 -382.

Vega, S. H. and Elhorst, J. P. (2015). The SLX model. Journal of Regional Science 55: 339-363. 
Weiss, C. R. (1999). Farm growth and survival: Econometric evidence for individual farms in upper austria. American Journal of Agricultural Economics 81: 103-116.

Willock, J., Deary, I. J., Edwards-Jones, G., Gibson, G. J., McGregor, M. J., Sutherland, A., Dent, J. B., Morgan, O. and Grieve, R. (1999). The role of attitudes and objectives in farmer decision making: Business and environmentally-oriented behaviour in scotland. Journal of Agricultural Economics 50: 286-303.

Zimmermann, A. and Heckelei, T. (2012). Structural change of european dairy farms-a crossregional analysis. Journal of Agricultural Economics 63: 576-603. 


\section{Appendix}

Table 5. Descriptive statistics of observed characteristics by farm type endogenously identified by the mixed probit model.

\begin{tabular}{|c|c|c|c|c|c|c|}
\hline \multirow[t]{2}{*}{ Farm characteristic } & \multicolumn{2}{|c|}{ Type1 } & \multicolumn{2}{|c|}{ Type2 } & \multicolumn{2}{|c|}{ Type3 } \\
\hline & Means & St. Dev. & Means & St. Dev. & Means & St. Dev. \\
\hline Total UAA & 44.53 & 51.97 & 50.96 & 59.12 & 48.25 & 50.81 \\
\hline Per partner agricultural profit & 8.86 & 9.91 & 11.03 & 12.76 & 11.35 & 13.13 \\
\hline Median age of farm holders & 49.22 & 10.12 & 48.28 & 9.53 & 47.75 & 7.70 \\
\hline Low-land-use farms & 0.07 & 0.26 & 0.06 & 0.24 & 0.07 & 0.25 \\
\hline Mid-land-use farms & 0.31 & 0.46 & 0.27 & 0.45 & 0.26 & 0.44 \\
\hline High-land-use farms & 0.62 & 0.49 & 0.67 & 0.47 & 0.67 & 0.47 \\
\hline Corporate legal status & 0.43 & 0.50 & 0.48 & 0.50 & 0.45 & 0.50 \\
\hline \multicolumn{7}{|l|}{ Municipality level } \\
\hline Deviation from average farm size & 4.19 & 52.86 & -2.44 & 59.03 & 0.72 & 50.58 \\
\hline Deviation from average agricultural profit & 1.67 & 10.10 & -0.35 & 12.63 & -0.56 & 12.98 \\
\hline Deviation from average median age of farm holders & -0.81 & 10.04 & -0.05 & 9.60 & 0.58 & 7.90 \\
\hline Share of less land use farms & 0.65 & 0.17 & 0.65 & 0.17 & 0.65 & 16.92 \\
\hline Share of corporate & 0.45 & 0.14 & 0.45 & 0.14 & 0.46 & 14.27 \\
\hline
\end{tabular}

Note: Low-land-use are farm specialisations with an average farm size less than 20 hectares; middle-land-use are farm specialisations with an average farm size between 20 and 50 hectares; high-land-use are farm specialisations with an average farm size more than 50 hectares; for each farm, own farm characteristics are excluded from the calculation of averages and shares at the municipality level.

Source: MSA COTNS database, Brittany 2004-2014 - authors' calculations 


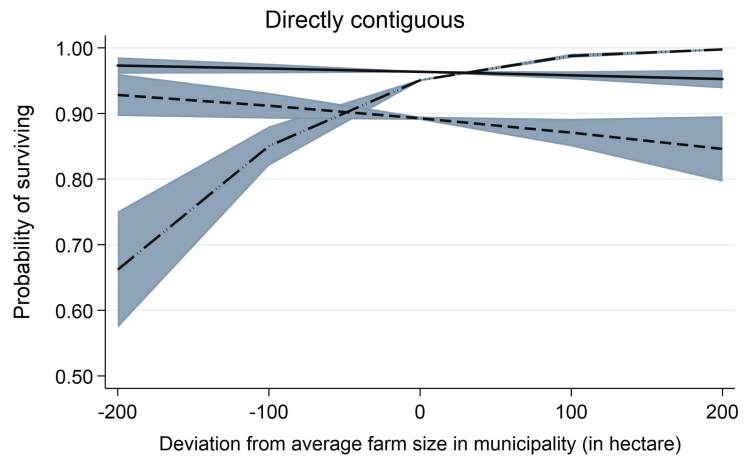

- - - Type 1 ----- Type 2 Type 3

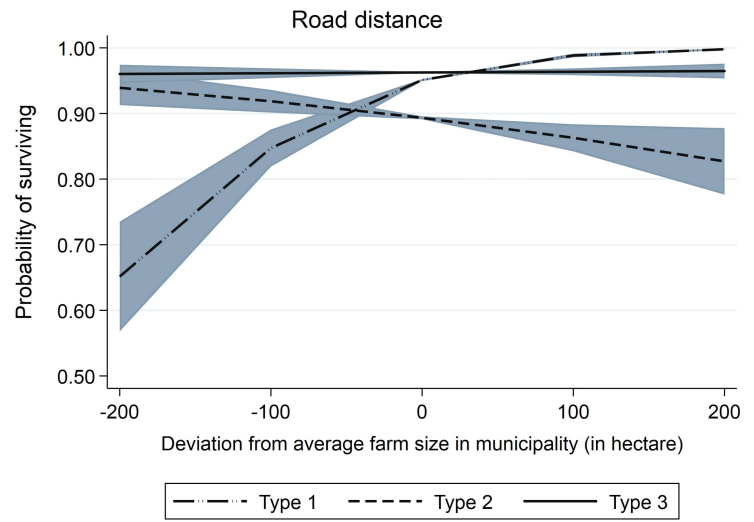

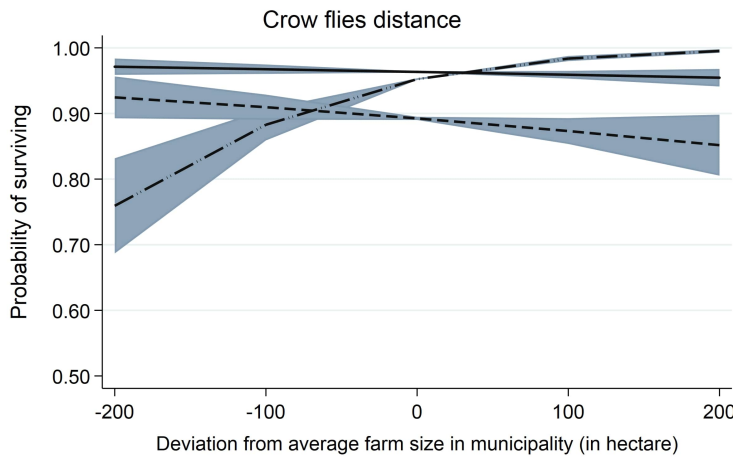

- - - Type 1 ----- Type 2 Type 3

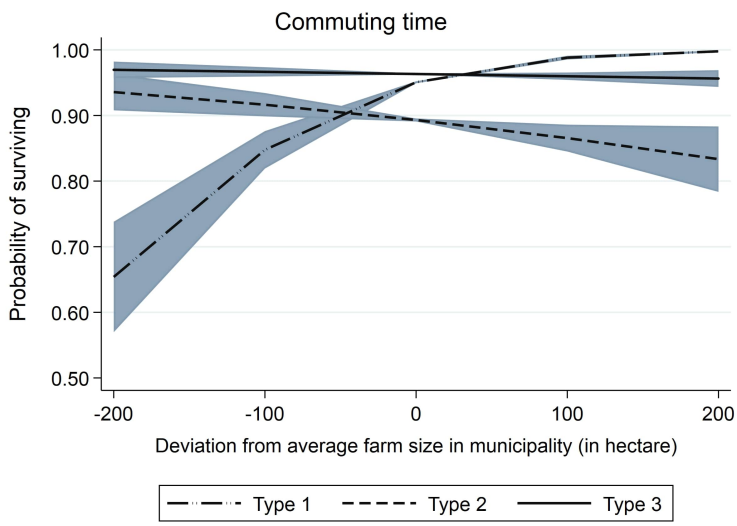

Fig. 4. Predicted probability of farm survival for varying levels of average farm size by unobserved farm type by the neighbourhood definition considered.

Note: Predicted probabilities with 95\% confidence intervals at the average values of the other explanatory variables are computed from the mixed probit estimations using four different spatial weighting matrix (W) definitions. The mixed probit model is are estimated considering as neighbours all farms whose farmstead is located in municipalities: which are directly contiguous (panel 'directly contiguous'); whose centroid is not further than 6.5 kilometres as the crow flies (panel 'crow flies distance'); which are not further than 8 kilometers by the road (panel 'road distance'); and for which the commuting time is not more than 10 minutes (panel 'commuting time'). For each farm, own area is excluded from the calculation of the average farm area in municipality.

Source: MSA COTNS database, Brittany 2004-2014 - authors' calculations 
Table 6. Estimated parameters for both the pooled and the mixture of probit models, considering as neighbours all farms whose farmstead is located in municipalities which are directly contiguous.

\begin{tabular}{|c|c|c|c|c|c|c|c|c|c|c|}
\hline \multirow{3}{*}{ Variable code } & \multirow{2}{*}{\multicolumn{2}{|c|}{$\begin{array}{l}\text { Pooled } \\
\text { Probit }\end{array}$}} & \multicolumn{8}{|c|}{ Mixed Probit } \\
\hline & & & \multicolumn{2}{|c|}{ Type 1} & \multicolumn{2}{|c|}{ Type 2} & \multicolumn{2}{|c|}{ Type 3} & \multicolumn{2}{|c|}{ Aggregate } \\
\hline & Estimate & Std. Err. & Estimate & Std. Err. & Estimate & Std. Err. & Estimate & Std. Err. & Estimate & Std. Err. \\
\hline intercept & -0.2586 & $(0.3241)$ & -0.1697 & $(0.4460)$ & $-1.3712^{* * *}$ & $(0.3716)$ & $-56.2298 * * *$ & $(1.2140)$ & -17.0555 & $(0.4107)$ \\
\hline time_trend & $0.0092^{* *}$ & $(0.0030)$ & $-0.0247^{* * *}$ & $(0.0041)$ & $-0.0256^{* * *}$ & $(0.0035)$ & $0.1139^{* * *}$ & $(0.0093)$ & $0.0150^{* * *}$ & $(0.0034)$ \\
\hline area & $0.0030^{* * *}$ & $(0.0006)$ & 0.0007 & $(0.0008)$ & $0.0055^{* * *}$ & $(0.0006)$ & -0.0006 & $(0.0018)$ & $0.0028^{* * *}$ & $(0.0006)$ \\
\hline area_square & $-3.84 \mathrm{E}-07^{* * *}$ & $(2.34 \mathrm{E}-08)$ & $4.99 \mathrm{E}-06^{* * *}$ & $(5.74 \mathrm{E}-07)$ & $-7.53 \mathrm{E}-07^{* * *}$ & $(2.28 \mathrm{E}-08)$ & $3.80 \mathrm{E}-05^{* * *}$ & $(6.05 \mathrm{E}-06)$ & $1.16 \mathrm{E}-05^{* * *}$ & $(1.76 \mathrm{E}-06)$ \\
\hline agri_profit & 0.0043 & $(0.0022)$ & $-0.0179 * * *$ & $(0.0031)$ & $0.0076^{* *}$ & $(0.0026)$ & $0.0480 * * *$ & $(0.0081)$ & $0.0145^{* * *}$ & $(0.0028)$ \\
\hline median_age & $0.0293^{* * *}$ & $(0.0051)$ & $0.0163^{*}$ & $(0.0069)$ & $0.0243^{* * *}$ & $(0.0058)$ & $3.0045^{* * *}$ & $(0.0335)$ & $0.8870^{* * *}$ & $(0.0103)$ \\
\hline median_age_square & $-0.0003^{* * *}$ & $(2.24 \mathrm{E}-05)$ & $1.18 \mathrm{E}-05$ & $(3.15 \mathrm{E}-05)$ & $-1.37 \mathrm{E}-04^{* * *}$ & $(2.53 \mathrm{E}-05)$ & $-0.0366^{* * *}$ & $(0.0003)$ & $-0.0107^{* * *}$ & $(0.0001)$ \\
\hline agri_profit_X_closeretmt & $-0.0182^{* * *}$ & $(0.0006)$ & $-0.0282^{* * *}$ & $(0.0008)$ & $-0.0159^{* * *}$ & $(0.0006)$ & $-0.0481^{* * *}$ & $(0.0046)$ & $-0.0275^{* * *}$ & $(0.0014)$ \\
\hline lowlanduse & 0.0192 & $(0.0173)$ & $0.5605^{* * *}$ & $(0.0266)$ & $-0.0420^{*}$ & $(0.0193)$ & $0.2832^{* * *}$ & $(0.0546)$ & $0.1650^{* * *}$ & $(0.0194)$ \\
\hline middlelanduse & $0.0865^{* * *}$ & $(0.0132)$ & $0.2459^{* * *}$ & $(0.0171)$ & $0.0688^{* * *}$ & $(0.0140)$ & 0.0689 & $(0.0359)$ & $0.1019 * * *$ & $(0.0131)$ \\
\hline highlanduse_X_land & 0.0001 & $(0.0003)$ & 0.0001 & $(0.0004)$ & -0.0002 & $(0.0003)$ & -0.0008 & $(0.0009)$ & -0.0003 & $(0.0003)$ \\
\hline corporate & $0.3211^{* * *}$ & $(0.0090)$ & $1.0237^{* * *}$ & $(0.0129)$ & $0.3108^{* * *}$ & $(0.0099)$ & 0.0015 & $(0.0296)$ & $0.3544^{* * *}$ & $(0.0103)$ \\
\hline area_mun_deviation & -0.0001 & $(0.0005)$ & $0.0076^{* * *}$ & $(0.0007)$ & $-0.0012^{*}$ & $(0.0006)$ & -0.0024 & $(0.0016)$ & 0.0001 & $(0.0006)$ \\
\hline gini_mun & $-0.1088^{*}$ & $(0.0498)$ & $0.7182^{* * *}$ & $(0.0679)$ & $-0.2768^{* * *}$ & $(0.0570)$ & $-0.2966^{*}$ & $(0.1495)$ & -0.0965 & $(0.0541)$ \\
\hline agri_profit_mun_deviation & 0.0031 & $(0.0022)$ & $0.0263^{* * *}$ & $(0.0031)$ & 0.0029 & $(0.0026)$ & 0.0001 & $(0.0067)$ & $0.0065^{* *}$ & $(0.0024)$ \\
\hline median_age_mun_deviation & $0.0171^{* * *}$ & $(0.0044)$ & $0.0410^{* * *}$ & $(0.0059)$ & $0.0159^{* *}$ & $(0.0051)$ & $0.0522^{* * *}$ & $(0.0132)$ & $0.0311^{* * *}$ & $(0.0048)$ \\
\hline highlanduse_mun_share & 0.0121 & $(0.0479)$ & $0.1675^{*}$ & $(0.0657)$ & -0.0595 & $(0.0552)$ & 0.1463 & $(0.1437)$ & 0.0426 & $(0.0522)$ \\
\hline corporate_mun_share & -0.0293 & $(0.0836)$ & $-0.7750^{* * *}$ & $(0.1136)$ & 0.0732 & $(0.0954)$ & 0.3218 & $(0.2480)$ & -0.0134 & $(0.0901)$ \\
\hline average_sar_area & 0.0008 & $(0.0008)$ & 0.0013 & $(0.0011)$ & $0.0020^{*}$ & $(0.0010)$ & -0.0036 & $(0.0025)$ & $0.0003^{* * *}$ & $(0.0009)$ \\
\hline average_sar_agri_profit & $0.0101^{* * *}$ & $(0.0030)$ & $0.0317^{* * *}$ & $(0.0041)$ & $0.0125^{* * *}$ & $(0.0034)$ & $0.0284^{* *}$ & $(0.0093)$ & $0.0207^{* * *}$ & $(0.0033)$ \\
\hline average_sar_median_age & 0.0092 & $(0.0075)$ & 0.0100 & $(0.0101)$ & $0.0238^{* *}$ & $(0.0086)$ & $0.1269^{* * *}$ & $(0.0234)$ & $0.0511^{* * *}$ & $(0.0084)$ \\
\hline sar_highlanduse_share & $0.2308^{* * *}$ & $(0.0669)$ & $0.2101^{*}$ & $(0.0890)$ & $0.2911^{* * *}$ & $(0.0776)$ & $0.5612^{* *}$ & $(0.2034)$ & $0.3543^{* * *}$ & $(0.0735)$ \\
\hline sar_corporate_share & -0.1442 & $(0.1062)$ & -0.1442 & $(0.1447)$ & -0.1458 & $(0.1209)$ & $-1.0381^{* * *}$ & $(0.3263)$ & $-0.4043^{* * *}$ & $(0.1170)$ \\
\hline regional_unempl_rate & $0.0119 * * *$ & $(0.0036)$ & $0.0113^{*}$ & $(0.0048)$ & $0.0173^{* * *}$ & $(0.0041)$ & $0.0889 * * *$ & $(0.0108)$ & $0.0370^{* * *}$ & $(0.0039)$ \\
\hline Type shares & & & $18,68 \%$ & & $52,29 \%$ & & $29,03 \%$ & & $100 \%$ & \\
\hline Number of observations & 316,995 & & & & & & & & 316,995 & \\
\hline Log pseudo-likelihood & $-76,206$ & & & & & & & & $-73,577$ & \\
\hline
\end{tabular}

Note: area_mun_deviation, median_age_mun_deviation and agri_profit_mun_deviation are deviations from own farm characteristics and highlanduse_mun_share and corporate_mun_share are

neighbouring farm shares computed at the municipality level; average_sar_area, average_sar_median_age, sar_highlanduse_share and sar_corporate_share are averages and shares computed at the SAR level; *,** and *** indicate significance at $5 \%, 1 \%$ and $0.1 \%$ levels, respectively.

Source: MSA COTNS database, Brittany 2004-2014 - authors' calculations 
Table 7. Estimated parameters for both the pooled and the mixture of probit models, considering as neighbours all farms whose centroid is not further than 6.5 kilometres as the crow flies.

\begin{tabular}{|c|c|c|c|c|c|c|c|c|c|c|}
\hline \multirow{3}{*}{ Variable code } & \multirow{2}{*}{\multicolumn{2}{|c|}{$\begin{array}{l}\text { Pooled } \\
\text { Probit }\end{array}$}} & \multicolumn{8}{|c|}{ Mixed Probit } \\
\hline & & & \multicolumn{2}{|c|}{ Type 1} & \multicolumn{2}{|c|}{ Type 2} & \multicolumn{2}{|c|}{ Type 3} & \multicolumn{2}{|c|}{ Aggregate } \\
\hline & Estimate & Std. Err. & Estimate & Std. Err. & Estimate & Std. Err. & Estimate & Std. Err. & Estimate & Std. Err. \\
\hline intercept & -0.1973 & $(0.3228)$ & -0.3102 & $(0.4435)$ & $-1.2321 * * *$ & $(0.3699)$ & $-56.1681^{* * *}$ & $(1.2076)$ & $-17.1449^{* * *}$ & $(0.4115)$ \\
\hline time_trend & $0.0096^{* * *}$ & $(0.0030)$ & $-0.0251^{* * *}$ & $(0.0041)$ & $-0.0249 * * *$ & $(0.0035)$ & $0.1131^{* * *}$ & $(0.0093)$ & $0.0154^{* * *}$ & $(0.0034)$ \\
\hline area & $0.0030^{* * *}$ & $(0.0005)$ & -0.0006 & $(0.0008)$ & $0.0056^{* * *}$ & $(0.0006)$ & 0.0004 & $(0.0018)$ & $0.0028^{* * *}$ & $(0.0006)$ \\
\hline area_square & $-3.85 \mathrm{E}-07^{* * *}$ & $(2.34 \mathrm{E}-08)$ & $4.91 \mathrm{E}-06^{* * *}$ & $(5.71 \mathrm{E}-07)$ & $-7.50 \mathrm{E}-07^{* * *}$ & $(2.28 \mathrm{E}-08)$ & $3.71 \mathrm{E}-05^{* * *}$ & $(5.95 \mathrm{E}-06)$ & $1.11 \mathrm{E}-05^{* * *}$ & $(1.71 \mathrm{E}-06)$ \\
\hline agri_profit & $0.0048^{*}$ & $(0.0021)$ & $-0.0170 * * *$ & $(0.0029)$ & $0.0067^{* *}$ & $(0.0024)$ & $0.0477^{* * *}$ & $(0.0077)$ & $0.0149 * * *$ & $(0.0026)$ \\
\hline median_age & $0.0280^{* * *}$ & $(0.0046)$ & $0.0180^{* *}$ & $(0.0064)$ & $0.0215^{* * *}$ & $(0.0052)$ & $2.9756^{* * *}$ & $(0.0325)$ & $0.8872^{* * *}$ & $(0.0100)$ \\
\hline median_age_square & $-0.0003^{* * *}$ & $(2.24 \mathrm{E}-05)$ & $4.74 \mathrm{E}-06$ & $(3.15 \mathrm{E}-05)$ & $-0.0001^{* * *}$ & $(2.53 \mathrm{E}-05)$ & $-0.0365^{* * *}$ & $(0.0003)$ & $-0.0108^{* * *}$ & $(0.0001)$ \\
\hline agri_profit_X_closeretmt & $-0.0182^{* * *}$ & $(0.0006)$ & $-0.0281 * * *$ & $(0.0008)$ & $-0.0159^{* * *}$ & $(0.0006)$ & $-0.0479^{* * *}$ & $(0.0046)$ & $-0.0276^{* * *}$ & $(0.0014)$ \\
\hline lowlanduse & 0.0202 & $(0.0173)$ & $0.5449^{* * *}$ & $(0.0265)$ & $-0.0391^{*}$ & $(0.0193)$ & $0.2759^{* * *}$ & $(0.0544)$ & $0.1583^{* * *}$ & $(0.0194)$ \\
\hline middlelanduse & $0.0872^{* * *}$ & $(0.0132)$ & $0.2453^{* * *}$ & $(0.0171)$ & $0.0687^{* * *}$ & $(0.0140)$ & 0.0682 & $(0.0359)$ & $0.1009^{* * *}$ & $(0.0132)$ \\
\hline highlanduse_X_land & 0.0001 & $(0.0003)$ & 0.0002 & $(0.0004)$ & -0.0003 & $(0.0003)$ & -0.0009 & $(0.0009)$ & -0.0004 & $(0.0003)$ \\
\hline corporate & $0.3214^{* * *}$ & $(0.0090)$ & $1.0176^{* * *}$ & $(0.0129)$ & $0.3125^{* * *}$ & $(0.0099)$ & 0.0069 & $(0.0296)$ & $0.3551^{* * *}$ & $(0.0104)$ \\
\hline area_mun_deviation & -0.0002 & $(0.0005)$ & $0.0062^{* * *}$ & $(0.0007)$ & $-0.0011^{*}$ & $(0.0006)$ & -0.0015 & $(0.0015)$ & $8.50 \mathrm{E}-06$ & $(0.0006)$ \\
\hline gini_mun & -0.1116 & $(0.0506)$ & $0.7245^{* * *}$ & $(0.0693)$ & $-0.2872^{* * *}$ & $(0.0579)$ & -0.2676 & $(0.1517)$ & 0.0024 & $(0.0164)$ \\
\hline agri_profit_mun_deviation & 0.0036 & $(0.0021)$ & $0.0276^{* * *}$ & $(0.0029)$ & 0.0020 & $(0.0024)$ & -0.0001 & $(0.0063)$ & $0.0068^{* *}$ & $(0.0023)$ \\
\hline median_age_mun_deviation & $0.0157^{* * *}$ & $(0.0039)$ & $0.0418^{* * *}$ & $(0.0053)$ & $0.0132^{* *}$ & $(0.0045)$ & $0.0302^{* *}$ & $(0.0115)$ & $0.0224^{* * *}$ & $(0.0042)$ \\
\hline highlanduse_mun_share & 0.0313 & $(0.0439)$ & 0.0735 & $(0.0601)$ & -0.0119 & $(0.0506)$ & 0.0973 & $(0.1325)$ & 0.0566 & $(0.0478)$ \\
\hline corporate_mun_share & -0.0637 & $(0.0729)$ & $-0.6568 * * *$ & $(0.0994)$ & 0.0016 & $(0.0835)$ & 0.2227 & $(0.2179)$ & -0.0599 & $(0.0793)$ \\
\hline average_sar_area & 0.0008 & $(0.0008)$ & 0.0021 & $(0.0011)$ & $0.0021^{*}$ & $(0.0009)$ & -0.0043 & $(0.0025)$ & 0.0003 & $(0.0009)$ \\
\hline average_sar_agri_profit & $0.0091^{* *}$ & $(0.0029)$ & $0.0332^{* * *}$ & $(0.0040)$ & $0.0120^{* * *}$ & $(0.0034)$ & $0.0291^{* *}$ & $(0.0092)$ & $0.0202^{* * *}$ & $(0.0033)$ \\
\hline average_sar_median_age & 0.0094 & $(0.0073)$ & 0.0123 & $(0.0100)$ & $0.0236^{* *}$ & $(0.0084)$ & $0.1493^{* * *}$ & $(0.0229)$ & $0.0581^{* * *}$ & $(0.0082)$ \\
\hline sar_highlanduse_share & $0.2122^{* *}$ & $(0.0654)$ & $0.2584^{* *}$ & $(0.0867)$ & $0.2518^{* * *}$ & $(0.0759)$ & $0.5932^{* *}$ & $(0.1997)$ & $0.3384^{* * *}$ & $(0.0721)$ \\
\hline sar_corporate_share & -0.1043 & $(0.1006)$ & -0.2151 & $(0.1370)$ & -0.0737 & $(0.1148)$ & $-0.9379 * *$ & $(0.3127)$ & $-0.3355^{* *}$ & $(0.1122)$ \\
\hline regional_unempl_rate & $0.0119^{* * *}$ & $(0.0035)$ & 0.0081 & $(0.0048)$ & $0.0180^{* * *}$ & $(0.0041)$ & $0.0875^{* * *}$ & $(0.0108)$ & $0.0362^{* * *}$ & $(0.0039)$ \\
\hline Type shares & & & $18,65 \%$ & & $52,30 \%$ & & $29,05 \%$ & & $100 \%$ & \\
\hline Number of observations & 316,995 & & & & & & & & 316,995 & \\
\hline Log pseudo-likelihood & $-76,206$ & & & & & & & & $-73,578$ & \\
\hline
\end{tabular}

Note: area_mun_deviation, median_age_mun_deviation and agri_profit_mun_deviation are deviations from own farm characteristics and highlanduse_mun_share and corporate_mun_share are

neighbouring farm shares computed at the municipality level; average_sar_area, average_sar_median_age, sar_highlanduse_share and sar_corporate_share are averages and shares computed at the SAR level; *, ** and ${ }^{* * *}$ indicate significance at $5 \%, 1 \%$ and $0.1 \%$ levels, respectively.

Source: MSA COTNS database, Brittany 2004-2014 - authors' calculations 
Table 8. Estimated parameters for both the pooled and the mixture of probit models, considering as neighbours all farms which are not further than 8 kilometers by the road.

\begin{tabular}{|c|c|c|c|c|c|c|c|c|c|c|}
\hline \multirow{3}{*}{ Variable code } & \multirow{2}{*}{\multicolumn{2}{|c|}{$\begin{array}{l}\text { Pooled } \\
\text { Probit }\end{array}$}} & \multicolumn{8}{|c|}{ Mixed Probit } \\
\hline & & & \multicolumn{2}{|c|}{ Type 1} & \multicolumn{2}{|c|}{ Type 2} & \multicolumn{2}{|c|}{ Type 3} & \multicolumn{2}{|c|}{ Aggregate } \\
\hline & Estimate & Std. Err. & Estimate & Std. Err. & Estimate & Std. Err. & Estimate & Std. Err. & Estimate & Std. Err. \\
\hline intercept & -0.1937 & $(0.3227)$ & -0.3350 & $(0.4460)$ & $-1.2158^{* * *}$ & $(0.3698)$ & $-56.0197^{* * *}$ & $(1.2087)$ & $-16.7794^{* * *}$ & $(0.4094)$ \\
\hline time_trend & $0.0096^{* * *}$ & $(0.0030)$ & $-0.0259^{* * *}$ & $(0.0041)$ & $-0.0248^{* * *}$ & $(0.0035)$ & $0.1131^{* * *}$ & $(0.0093)$ & $0.0150^{* * *}$ & $(0.0033)$ \\
\hline area & $0.0030^{* * *}$ & $(0.0005)$ & 0.0006 & $(0.0008)$ & $0.0051^{* * *}$ & $(0.0006)$ & $0.0025^{* * *}$ & $(0.0017)$ & $0.0035^{* * *}$ & $(0.0006)$ \\
\hline area_square & $-3.84 \mathrm{E}-07^{* * *}$ & $(2.34 \mathrm{E}-08)$ & $5.12 \mathrm{E}-06^{* * *}$ & $(5.69 \mathrm{E}-07)$ & $-7.54 \mathrm{E}-07^{* * *}$ & $(2.28 \mathrm{E}-08)$ & $3.69 \mathrm{E}-05^{* * *}$ & $(6.00 \mathrm{E}-06)$ & $1.13 \mathrm{E}-05^{* * *}$ & $(1.74 \mathrm{E}-06)$ \\
\hline agri_profit & 0.0039 & $(0.0021)$ & $-0.0159 * * *$ & $(0.0029)$ & $0.0054^{*}$ & $(0.0024)$ & $0.0501^{* * *}$ & $(0.0077)$ & $0.0144^{* * *}$ & $(0.0026)$ \\
\hline median_age & $0.0247^{* * *}$ & $(0.0046)$ & $0.0187^{* *}$ & $(0.0064)$ & $0.0156^{* *}$ & $(0.0052)$ & $2.9720^{* * *}$ & $(0.0325)$ & $0.8735^{* * *}$ & $(0.0099)$ \\
\hline median_age_square & $-0.0003^{* * *}$ & $(2.24 \mathrm{E}-05)$ & $1.05 \mathrm{E}-05$ & $(3.17 \mathrm{E}-05)$ & $-0.0001^{* * *}$ & $(2.53 \mathrm{E}-05)$ & $-0.0365^{* * *}$ & $(0.0003)$ & $-0.0106^{* * *}$ & $(0.0001)$ \\
\hline agri_profit_X_closeretmt & $-0.0182^{* * *}$ & $(0.0006)$ & $-0.0280^{* * *}$ & $(0.0008)$ & $-0.0159^{* * *}$ & $(0.0006)$ & $-0.0477^{* * *}$ & $(0.0046)$ & $-0.0274^{* * *}$ & $(0.0014)$ \\
\hline lowlanduse & 0.0209 & $(0.0173)$ & $0.5613^{* * *}$ & $(0.0268)$ & $-0.0399^{*}$ & $(0.0192)$ & 0.2833 & $(0.0544)$ & $0.1656^{* * *}$ & $(0.0194)$ \\
\hline middlelanduse & $0.0876^{* * *}$ & $(0.0132)$ & $0.2613^{* * *}$ & $(0.0172)$ & $0.0674^{* * *}$ & $(0.0140)$ & 0.0671 & $(0.0359)$ & $0.1034^{* * *}$ & $(0.0131)$ \\
\hline highlanduse_X_land & 0.0001 & $(0.0003)$ & 0.0002 & $(0.0004)$ & -0.0003 & $(0.0003)$ & -0.0009 & $(0.0009)$ & -0.0004 & $(0.0003)$ \\
\hline corporate & $0.3213^{* * *}$ & $(0.0090)$ & $1.0396^{* * *}$ & $(0.0130)$ & $0.3099^{* * *}$ & $(0.0099)$ & 0.0127 & $(0.0296)$ & $0.3594^{* * *}$ & $(0.0103)$ \\
\hline area_mun_deviation & -0.0001 & $(0.0005)$ & $0.0078^{* * *}$ & $(0.0007)$ & $-0.0016^{* *}$ & $(0.0006)$ & 0.0005 & $(0.0015)$ & 0.0008 & $(0.0005)$ \\
\hline gini_mun & -0.0979 & $(0.0502)$ & $0.7711^{* * *}$ & $(0.0688)$ & $-0.2744^{* * *}$ & $(0.0574)$ & -0.2853 & $(0.1503)$ & -0.0831 & $(0.0545)$ \\
\hline agri_profit_mun_deviation & 0.0027 & $(0.0021)$ & $0.0285^{* * *}$ & $(0.0029)$ & 0.0008 & $(0.0024)$ & 0.0025 & $(0.0062)$ & $0.0065^{* *}$ & $(0.0023)$ \\
\hline median_age_mun_deviation & $0.0124^{* * *}$ & $(0.0038)$ & $0.0435^{* * *}$ & $(0.0052)$ & 0.0072 & $(0.0044)$ & $0.0299 * *$ & $(0.0112)$ & $0.0206^{* * *}$ & $(0.0041)$ \\
\hline highlanduse_mun_share & 0.0334 & $(0.0435)$ & $0.2996^{* * *}$ & $(0.0598)$ & -0.0618 & $(0.0503)$ & 0.1378 & $(0.1325)$ & 0.0633 & $(0.0479)$ \\
\hline corporate_mun_share & -0.0511 & $(0.0724)$ & $-0.9037^{* * *}$ & $(0.1001)$ & 0.0735 & $(0.0830)$ & -0.1033 & $(0.2150)$ & $-0.1595^{*}$ & $(0.0783)$ \\
\hline average_sar_area & 0.0008 & $(0.0008)$ & 0.0013 & $(0.0011)$ & $0.0026^{* *}$ & $(0.0009)$ & $-0.0061^{*}$ & $(0.0024)$ & -0.0002 & $(0.0009)$ \\
\hline average_sar_agri_profit & $0.0101^{* * *}$ & $(0.0029)$ & $0.0316^{* * *}$ & $(0.0041)$ & $0.0135^{* * *}$ & $(0.0034)$ & $0.0260^{* *}$ & $(0.0092)$ & $0.0205^{* * *}$ & $(0.0033)$ \\
\hline average_sar_median_age & 0.0124 & $(0.0073)$ & 0.0106 & $(0.0100)$ & $0.0292^{* * *}$ & $(0.0084)$ & $0.1485^{* * *}$ & $(0.0227)$ & $0.0603^{* * *}$ & $(0.0081)$ \\
\hline sar_highlanduse_share & $0.2112^{* * *}$ & $(0.0653)$ & 0.0370 & $(0.0872)$ & $0.3020^{* * *}$ & $(0.0759)$ & $0.5403^{* *}$ & $(0.2005)$ & $0.3218^{* * *}$ & $(0.0723)$ \\
\hline sar_corporate_share & -0.1208 & $(0.0998)$ & $0.0110^{*}$ & $(0.1372)$ & -0.1480 & $(0.1139)$ & $-0.6326^{*}$ & $(0.3087)$ & $-0.2589^{*}$ & $(0.1106)$ \\
\hline regional_unempl_rate & $0.0119^{* * *}$ & $(0.0035)$ & 0.0122 & $(0.0048)$ & $0.0174^{* * *}$ & $(0.0041)$ & $0.0867^{* * *}$ & $(0.0107)$ & $0.0365^{* * *}$ & $(0.0039)$ \\
\hline Type shares & & & $18,60 \%$ & & $52,36 \%$ & & $29,04 \%$ & & $100 \%$ & \\
\hline Number of observations & 316,995 & & & & & & & & 316,995 & \\
\hline Log pseudo-likelihood & $-76,209$ & & & & & & & & $-73,575$ & \\
\hline
\end{tabular}

Note: area_mun_deviation, median_age_mun_deviation and agri_profit_mun_deviation are deviations from own farm characteristics and highlanduse_mun_share and corporate_mun_share are

neighbouring farm shares computed at the municipality level; average_sar_area, average_sar_median_age, sar_highlanduse_share and sar_corporate_share are averages and shares computed at the SAR level; *,** and *** indicate significance at $5 \%, 1 \%$ and $0.1 \%$ levels, respectively.

Source: MSA COTNS database, Brittany 2004-2014 - authors' calculations 
Table 9. Estimated parameters for both the pooled and the mixture of probit models, considering as neighbours all farms for which the commuting time is not more than 10 minutes.

\begin{tabular}{|c|c|c|c|c|c|c|c|c|c|c|}
\hline \multirow{3}{*}{ Variable code } & \multirow{2}{*}{\multicolumn{2}{|c|}{$\begin{array}{l}\text { Pooled } \\
\text { Probit }\end{array}$}} & \multicolumn{8}{|c|}{ Mixed Probit } \\
\hline & & & \multicolumn{2}{|c|}{ Type 1} & \multicolumn{2}{|c|}{ Type 2} & \multicolumn{2}{|c|}{ Type 3} & \multicolumn{2}{|c|}{ Aggregate } \\
\hline & Estimate & Std. Err. & Estimate & Std. Err. & Estimate & Std. Err. & Estimate & Std. Err. & Estimate & Std. Err. \\
\hline intercept & -0.1500 & $(0.3227)$ & -0.3741 & $(0.4448)$ & $-1.1601^{* *}$ & $(0.3700)$ & $-56.6600^{* * *}$ & $(1.2194)$ & $-16.9297^{* * *}$ & $(0.4111)$ \\
\hline time_trend & $0.0100^{* * *}$ & $(0.0030)$ & $-0.0253^{* * *}$ & $(0.0041)$ & $-0.0243^{* * *}$ & $(0.0035)$ & $0.1143^{* * *}$ & $(0.0094)$ & $0.0155^{* * *}$ & $(0.0033)$ \\
\hline area & $0.0029^{* * *}$ & $(0.0005)$ & 0.0009 & $(0.0008)$ & $0.0052^{* * *}$ & $(0.0006)$ & 0.0007 & $(0.0018)$ & $0.0031^{* * *}$ & $(0.0006)$ \\
\hline area_square & $-3.84 \mathrm{E}-07^{* * *}$ & $(2.34 \mathrm{E}-08)$ & $5.13 \mathrm{E}-06^{* * *}$ & $(5.65 \mathrm{E}-07)$ & $-7.53 \mathrm{E}-07^{* * *}$ & $(2.28 \mathrm{E}-08)$ & $3.76 \mathrm{E}-05^{* * *}$ & $(5.97 \mathrm{E}-06)$ & $1.11 \mathrm{E}-05^{* * *}$ & $(1.72 \mathrm{E}-06)$ \\
\hline agri_profit & $0.0047^{* *}$ & $(0.0019)$ & $-0.0234^{* * *}$ & $(0.0027)$ & $0.0075^{* * *}$ & $(0.0022)$ & $0.0510^{* * *}$ & $(0.0074)$ & $0.0148^{* * *}$ & $(0.0025)$ \\
\hline median_age & $0.0228^{* * *}$ & $(0.0041)$ & -0.0049 & $(0.0056)$ & $0.0166^{* * *}$ & $(0.0046)$ & $3.0013^{* * *}$ & $(0.0324)$ & $0.8754^{* * *}$ & $(0.0097)$ \\
\hline median_age_square & $-0.0003^{* * *}$ & $(2.24 \mathrm{E}-05)$ & $1.43 \mathrm{E}-05$ & $(3.17 \mathrm{E}-05)$ & $-0.0001 * * *$ & $(2.53 \mathrm{E}-05)$ & $-0.0369^{* * *}$ & $(0.0003)$ & $-0.0108^{* * *}$ & $(0.0001)$ \\
\hline agri_profit_X_closeretmt & $-0.0182^{* * *}$ & $(0.0006)$ & $-0.0281 * * *$ & $(0.0008)$ & $-0.0159^{* * *}$ & $(0.0006)$ & $-0.0481^{* * *}$ & $(0.0045)$ & $-0.0275^{* * *}$ & $(0.0014)$ \\
\hline lowlanduse & 0.0187 & $(0.0174)$ & $0.5450^{* * *}$ & $(0.0267)$ & $-0.0423^{*}$ & $(0.0193)$ & $0.2912^{* * *}$ & $(0.0551)$ & $0.1594^{* * *}$ & $(0.0195)$ \\
\hline middlelanduse & $0.0862^{* * *}$ & $(0.0132)$ & $0.2411^{* * *}$ & $(0.0172)$ & $0.0671^{* * *}$ & $(0.0141)$ & $0.0763^{*}$ & $(0.0363)$ & 0.1014 & $(0.0132)$ \\
\hline highlanduse_X_land & 0.0001 & $(0.0003)$ & 0.0002 & $(0.0004)$ & -0.0003 & $(0.0003)$ & -0.0007 & $(0.0009)$ & -0.0003 & $(0.0003)$ \\
\hline corporate & $0.3222^{* * *}$ & $(0.0091)$ & $1.0339^{* * *}$ & $(0.0130)$ & $0.3104^{* * *}$ & $(0.0100)$ & 0.0062 & $(0.0299)$ & $0.3565^{* * *}$ & $(0.0104)$ \\
\hline area_mun_deviation & -0.0002 & $(0.0005)$ & $0.0081^{* * *}$ & $(0.0007)$ & $-0.0015^{* *}$ & $(0.0006)$ & -0.0012 & $(0.0015)$ & 0.0003 & $(0.0005)$ \\
\hline gini_mun & -0.1189 & $(0.0517)$ & $0.7855^{* * *}$ & $(0.0707)$ & $-0.2979 * * *$ & $(0.0589)$ & -0.1985 & $(0.1563)$ & 0.0076 & $(0.0166)$ \\
\hline agri_profit_mun_deviation & $0.0035^{*}$ & $(0.0019)$ & $0.0210^{* * *}$ & $(0.0027)$ & 0.0029 & $(0.0022)$ & 0.0030 & $(0.0060)$ & $0.0068^{* *}$ & $(0.0021)$ \\
\hline median_age_mun_deviation & $0.0105^{* *}$ & $(0.0033)$ & $0.0203^{* * *}$ & $(0.0044)$ & $0.0081^{*}$ & $(0.0037)$ & $0.0220^{*}$ & $(0.0101)$ & $0.0137^{* * *}$ & $(0.0036)$ \\
\hline highlanduse_mun_share & 0.0093 & $(0.0428)$ & -0.0050 & $(0.0586)$ & -0.0503 & $(0.0493)$ & 0.1998 & $(0.1324)$ & 0.0509 & $(0.0468)$ \\
\hline corporate_mun_share & -0.0870 & $(0.0654)$ & $-0.5928^{* * *}$ & $(0.0873)$ & 0.0095 & $(0.0748)$ & 0.0953 & $(0.2019)$ & -0.0781 & $(0.0721)$ \\
\hline average_sar_area & 0.0009 & $(0.0008)$ & 0.0008 & $(0.0011)$ & $0.0025^{* *}$ & $(0.0009)$ & $-0.0050^{*}$ & $(0.0025)$ & 0.0001 & $(0.0009)$ \\
\hline average_sar_agri_profit & $0.0090^{* *}$ & $(0.0029)$ & $0.0428^{* * *}$ & $(0.0040)$ & $0.0105^{* *}$ & $(0.0034)$ & $0.0253^{* *}$ & $(0.0092)$ & $0.0204^{* * *}$ & $(0.0033)$ \\
\hline average_sar_median_age & 0.0137 & $(0.0071)$ & $0.0353^{* * *}$ & $(0.0096)$ & $0.0274^{* * *}$ & $(0.0082)$ & $0.1561^{* * *}$ & $(0.0225)$ & $0.0664^{* * *}$ & $(0.0080)$ \\
\hline sar_highlanduse_share & $0.2371^{* * *}$ & $(0.0646)$ & $0.3284^{* * *}$ & $(0.0854)$ & $0.2924^{* * *}$ & $(0.0751)$ & $0.5382^{* *}$ & $(0.1997)$ & $0.3544^{* * *}$ & $(0.0713)$ \\
\hline sar_corporate_share & -0.0904 & $(0.0951)$ & $-0.3258^{*}$ & $(0.1286)$ & -0.0813 & $(0.1083)$ & $-0.8323^{* *}$ & $(0.3008)$ & $-0.3331^{* * *}$ & $(0.1066)$ \\
\hline regional_unempl_rate & $0.0119^{* * *}$ & $(0.0035)$ & 0.0055 & $(0.0048)$ & $0.0183^{* * *}$ & $(0.0041)$ & $0.0893^{* * *}$ & $(0.0108)$ & $0.0363^{* * *}$ & $(0.0039)$ \\
\hline Type shares & & & $18,79 \%$ & & $52,27 \%$ & & $28,94 \%$ & & $100 \%$ & \\
\hline Number of observations & 316,995 & & & & & & & & 316,995 & \\
\hline Log pseudo-likelihood & $-76,208$ & & & & & & & & $-73,574$ & \\
\hline
\end{tabular}

Note: area_mun_deviation, median_age_mun_deviation and agri_profit_mun_deviation are deviations from own farm characteristics and highlanduse_mun_share and corporate_mun_share are

neighbouring farm shares computed at the municipality level; average_sar_area, average_sar_median_age, sar_highlanduse_share and sar_corporate_share are averages and shares computed at the SAR level; *, ** and $* * *$ indicate significance at $5 \%, 1 \%$ and $0.1 \%$ levels, respectively.

Source: MSA COTNS database, Brittany 2004-2014 - authors' calculations 